\title{
Causal mapping as a teaching tool for reflecting on causation in human evolution
}

Susan Hanisch, Dr. rer. nat.

Dept. of Comparative Cultural Psychology

Max Planck Institute for Evolutionary Anthropology

Leipzig, Germany

susan.hanisch@eva.mpg.de

Dustin Eirdosh, MSc.

Dept. of Comparative Cultural Psychology

Max Planck Institute for Evolutionary Anthropology

Leipzig, Germany

dustin.eirdosh@eva.mpg.de 


\section{Abstract}

Teleological reasoning is viewed as a major hurdle to evolution education, and yet, eliciting, interpreting, and reflecting upon teleological language presents an arguably greater challenge to the evolution educator and researcher. This article argues that making explicit the role of behavior as a causal factor in the evolution of particular traits may prove productive in helping students to link their everyday experience of behavior to evolutionary changes in populations in ways congruent with scientific perspectives. We present a teaching tool, used widely in other parts of science and science education, yet perhaps underutilized in human evolution education - the causal map - as a novel direction for driving conceptual change in the classroom about the nature of evolutionary change. After describing the scientific and conceptual basis for using such causal maps in human evolution education, we describe a classroom intervention within the context of a larger Design-Based Implementation Research (DBIR) project. An overview of the teacher-researcher collaborative design process and preliminary results from classroom interventions using causal maps within a human evolution unit are described. Initial results of the interventions indicate that causal maps allow students to make visible their causal reasoning about complex processes in human evolution, and can facilitate classroom reflection and conceptual change. Based on these insights, we offer considerations for future research and educational design.

Keywords: teleology, human evolution, causal mapping, behavior 
$\begin{array}{ll}\text { Abstract } & 2\end{array}$

Introduction $\quad 3$

The problem of defining teleological reasoning 4

Students' explanations may not reflect problematic teleological conceptions $\quad 5$

Teleological reasoning in different types of causal explanation 6

Clarifying the evolutionary consequences of behaviors for evolution education - Perspectives from evolutionary and developmental biology

Causal mapping for teaching behavior as selection pressure

Example: Evolution of upright walking

Causal mapping classroom engagement example

Description of the teacher-researcher collaboration and design process 32

First iteration: 12th grade biology class $\quad 32$

2nd iteration: 10th grade class 33

3rd iteration: 10th grade class $\quad 37$

Considerations for further research and development $\quad 42$

List of abbreviations $\quad 43$

$\begin{array}{ll}\text { Declarations } & 43\end{array}$

$\begin{array}{ll}\text { Acknowledgements } & 44\end{array}$

$\begin{array}{ll}\text { References } & 44\end{array}$

\section{Introduction}

Humans are an evolved species with an elaborate capacity to develop and act on our own intentions, and those we perceive in others. These evolved capacities for the perception of needs, for goal-directed behavior in response to those needs, and for intentional reasoning are known to pose challenges in understanding evolutionary processes. Evolution educators and students alike may find it challenging to resolve the populational and stochastic aspects of evolutionary processes with the directed changes associated with our experience of needs and intentional action. Such challenges to evolution education are one facet of a broader class of teleological reasoning, the appeal to function, need, or purpose in evolutionary explanations. 
Even in light of such challenges, many education researchers have highlighted the potential for human evolution examples to cultivate understanding of general evolutionary concepts, e.g. because the topic is engaging, connects to students' lives, or because concepts like variation are more salient in our own species (Besterman \& Baggot la Velle, 2007; Nettle, 2010; Pobiner, 2016; Pobiner et al., 2018; Werth, 2009). Furthermore, because it concerns our own species, an arguably richer diversity of empirical research exists about the causes of our human traits. Paleoanthropologists, paleoclimatologists, evolutionary anthropologists, archeologists, comparative psychologists, primatologists, and geneticists are among the scientists each contributing methods and lines of evidence about similarities, differences and evolutionary changes in environment, behavior, cognition, morphology, brain, genes, social organization and culture in humans and other primates. These diverse streams of inquiry may help us construct a more interdisciplinary account of the evolution of our species, compared to other examples in biology education.

In this paper, we aim to show that these interdisciplinary strengths of human evolution science may also offer opportunities to address a number of issues regarding teleological reasoning in evolution education. In the following sections, we review how the concept of teleological reasoning has been defined in different ways, and that there remains debate regarding how or if student answers to specific prompts should be considered as incorrectly teleological. We argue that-more explicit clarification and exploration of the causal role of behavioral variation, often in response to perceived needs and preferences, in the evolution of certain traits, and visualization of these dynamics through the use of causal maps, may help students to link everyday conceptions about the role of behaviors and needs, to the mechanisms of evolutionary change.

\section{The problem of defining teleological reasoning}

Teleological reasoning has been defined in many different ways by biologists and philosophers (Mayr, 1974) as well as education researchers. In the evolution education literature specifically, we find variations in the framing of teleological explanations such as reference to purpose (Legare et al., 2013), reference to function (Kelemen, 2012), reference to the consequences rather than an antecedent of an event (Coley \& Tanner, 2015), or viewing natural phenomena as purposeful (Barnes et al., 2017). In earlier recognition of the challenges posed by issues of teleological reasoning in biological causation, biologists coined the term teleonomy (Pittendrigh, 1958) to frame apparent goal-directedness in living 
systems within naturalistic causal explanation. Teleonomy refers to the fact that organisms do have goal-directed behaviors, which, just as many other traits, are outcomes of natural selection. In this article, we leave aside the kind of creationist teleology that posits the actions of a purposeful creator, and focus only on the problem of what Evans and Rosengren (2018) term teleological realism - naturalistic explanations rooted in the needs of living organisms.

Within teleological realist conceptions, further distinctions have also been made, each thought to indicate different underlying reasoning styles, and each drawing attention to more specific educational challenges and opportunities. For example, Legare et al. (2013) distinguish between need and desire-based explanations, Kelemen (2012) identifies categories of "basic function-based"; "basic need-based"; and "elaborated need-based" explanations. Our focus is on these varieties of need-based conceptions in relation to teaching for conceptual change in human evolution.

\section{Students' explanations may not reflect problematic teleological conceptions}

Besides the complexity of how teleological reasoning is defined and differentiated, there is the related complex discussion regarding whether apparent teleological language from students can be interpreted as faulty biological reasoning.

Education researchers have pointed out that often, we do not really know what a student is thinking because students are not given more prompts and opportunities to elaborate on their thinking (Kelemen, 2012; Kampourakis \& Nehm, 2014 ; Gouvea \& Simon, 2018). Categorizing short student explanations based on simple phrases that students might use such as "in order to", "so that", "because it needs it", may be problematic because these tell us very little about the nuances of their thinking. Gouvea \& Simon (2018) and Louca et al. (2004) argue that students' explanations or endorsement of explanations may be much more context-dependent and dynamic compared to a view that these represent relatively stable cognitive frameworks for evolutionary reasoning.

Importantly, in this regard it has also been argued that teleological reasoning per se is not necessarily a problem (Varella, 2018; Legare et al., 2018; Zohar \& Ginossar, 1998). Our evolved human tendency to see functions, goals, and purposes can be appropriate and 
helpful in exploring the causes and functions of biological phenomena and explaining them to others. Such reasoning may foster "new research questions and discoveries when asking for reasons, roles, goals, strategies, and values using 'why?' and 'what for?' questions" (Varella, 2018). Similarly, Mayr (1974) stated that "[t]he teleological dilemma (...) consists in the fact that numerous and seemingly weighty objections against the use of teleological language have been raised by various critics, and yet biologists have insisted that they would lose a great deal, methodologically and heuristically, if they were prevented from using such language." (p. 136). According to Varella (2018), teleological reasoning becomes problematic, among others, when: it is misapplied to all aspects within a domain, such as when all phenomena in biology are explained by having a function (adaptationism), or when attributing internal desires or needs to all actions of biological agents (fundamental attribution error), or when attributing intention to all human actions (intentionality bias); or when it is misapplied to a different domain, such as when human-specific mental states such as explicit beliefs are misapplied to other biological organisms (anthropomorphic reasoning).

\section{Teleological reasoning in different types of causal explanation}

Some of the difficulty with identifying student reasoning as unscientifically "teleological" may also have to do with the fact that biological phenomena such as organism traits (e.g. behaviors, morphology, physiology) can be explained by different types of causes, which are not mutually exclusive but complementary, addressing different aspects of a full causal account. Two common frameworks employed in biology to distinguish between types of causes are Tinbergen's four questions (Tinbergen, 1963) and Mayr's distinction between proximate and ultimate causes (Mayr, 1961). For example, in terms of Tinbergen's questions, an observable behavior can be explained by its more immediate mechanisms (environmental stimuli, senses, nervous system function, mental states, physiology, etc.), by referring to its developmental history, by referring to the function that the behavior had and currently has for the organism itself and/or for its ancestors in terms of survival and reproduction (thus whether it might have come about by natural selection), and by the phylogenetic history of the trait. Explanations of a phenomenon with causes immediately preceding or lying in the individual developmental past are often equated with Mayr's proximate explanations, while explanations involving function and phylogenetic history are often equated with Mayr's ultimate explanations (Dewsbury, 1992; Hladký \& Havlíček, 2013; Laland et al., 2012). 
Of particular interest to the evolution education community is the role of teleological reasoning in explaining the ultimate or evolutionary causes of observed organism traits. When eliciting student explanations of evolutionary causes, two different aspects seem to be of concern: on the one hand is the question of to what degree explanations include a role of proximate mechanisms such as goals, preferences, behaviors, including behavioral responses to the perceived needs of organisms, in the evolution of a trait. On the other hand is the question of to what degree evolution itself is considered to have a goal or proceed towards a goal or direction.

We suspect that often, it may not be made clear to students what kind of causal explanation is expected of them, which may lead to educators incorrectly identifying a reasoning style as "wrong" or "teleological" (Gouvea \& Simon, 2018; Louca et al., 2004), when it may be an adequate response based on student interpretations of less specific prompts. Lombrozo (2009) manipulated prompts by asking students questions such as "Why do flowers have trait X", and some students were also asked for a functional explanation such as "What purpose might X serve?", and found that the large majority of students' explanations referenced proximate mechanism or function based on the nature of the question. Thus, students may sometimes be giving proximate explanations (including cognitive processes, such as "it feels like doing X", "it wants to do X") or functions ("it needs to do X", "it has the trait so that it can do $\left.X^{\prime \prime}\right)$, when explanations of a mechanism of past natural selection are expected of them - the problem being that this reference to cognitive processes, need, or function does not in itself explain how a trait came about through natural selection. For example, Coley \& Tanner (2015) considered students' reference to a function as teleological, because they considered only reference to past events as appropriate. However, function is often an important aspect of a biologically appropriate explanation for the existence of a trait (see Tinbergen's questions above) whereby it is implied that the trait's function is an antecedent cause for its existence. Nehm et al. (2012) state that "Students often believe it is not possible to solve the problem [of how a trait evolved] without knowing how the trait functions, which likely indicates the absence of an abstract model of natural selection". However, without knowing about whether and what functions a trait might fulfill (including possible detrimental or neutral consequences), it is unclear how one can correctly reason about its evolution without, for example, committing other reasoning errors such as adaptationism. Kelemen (2012) categorised as "basic need-based" those explanations which "do not elaborate any actual mechanism of change. This is true even though a biological survival need (...) is invoked as an antecedent causal trigger. Absent any explicit 
reference to underlying mechanism, basic need-based explanations therefore carry the implication that an animal's biological need has an intrinsic power to bring a heritable trait into existence by having direct transformational effects on an animal's underlying (genetic) nature". However, it may not necessarily be the case that one can infer this simply from such a student explanation. Note also that in the above quote, the phrasing "biological (survival) need" is used in a way that, by itself, does not seem to be considered problematic.

In fact, it has been argued that explanations referencing "need" or "function" for the existence of a biological phenomenon may be a shorthand intuitive understanding that the consequences of the need or function in the past would have brought about the phenomenon in the population, even if no explicit causal mechanism is given (Gouvea \& Simon; 2018; Lombrozo \& Vasilyeva, 2017; Wright, 1976). This is in line with the point made by Evans \& Rosengren (2018) that need-based explanations (as opposed to desire-based explanations) may provide a bridge towards biological explanations of evolutionary change by natural selection. Other educators on the other hand, seem to engage in a practice whereby students' use of the term "need" is being actively discouraged or suppressed, such as through "booing" as soon as a student utters this word (Bravo \& Cofré, 2016). There seems to be thus no strong consensus in the evolution education community regarding whether the use of the word "need" as such is problematic, or whether it is rather the lack of integration of biological needs of organism with the mechanism of natural selection.

In this regard, it is also noteworthy that the concept of "need" is often referenced and defined in biology science communication and textbooks. For example, Aunger \& Curtis (2008) define need as "A task related to an evolutionarily significant aspect of an animal's ecological niche which requires goal-directed behaviour to solve". Fuentes (2019), in his textbook on biological anthropology, relates the concept of need to "socioecological selection pressures" and states that "All animals are subject to five basic kinds of challenges: the need to obtain food, to move around their habitat, to protect themselves from predators, and to compete for resources both with members of their own species and with other species." (p. 130, emphasis added).

Furthermore, when young students answer questions such as "What are trees for?" with "So that birds can live in them", this might not imply that they really think trees were made for this purpose, but that from the perspective of a bird, this is what a tree can be used for. Ojalehto et al. (2013) refer to this as relational-deictic reasoning style and highlight that in 
such instances, students might be thinking about valid ecological relationships among organisms and their environment, rather than a belief that things in nature are designed for a purpose, outside of that ecological relationship.

In this article, we aim to highlight how these concerns for teleological reasoning might be addressed by helping students to link proximate and ultimate explanations towards a biologically appropriate causal account of organism traits in evolution generally, and in human evolution in particular. In the next section, we review discourse and findings in evolutionary and developmental biology of the last decades about the role of behaviors as causal factors in evolutionary change. We then introduce the use of causal maps in the classroom as a tool to help students and teachers reflect carefully on the specific (proximate) interactions between environments, organism behaviors and other traits, and how these interactions can lead to (ultimate) population level changes over evolutionary time. We provide an example of the use of such causal maps in reflecting on the evolution of upright walking in human evolution, and report on a classroom intervention using such causal maps within a design-based implementation research project.

\section{Clarifying the evolutionary consequences of}

\section{behaviors for evolution education - Perspectives from evolutionary and developmental biology}

Evolution is a process by which small changes and interactions in the proximate time scale can have large population-level consequences in the phylogenetic time scale. How behavioral variation plays into these processes is a subject of much discussion in evolutionary biology. In this section, we argue that a renewed recognition within evolutionary biology of behaviors as significant drivers of (rather than merely outcomes of) evolution, may provide opportunities for evolution education, namely by building on students' existing intuitive conceptions regarding the role of need, including individual behavioral responses to need, as causal factors in evolutionary change.

A comprehensive review of the sociology and history of evolutionary theory is beyond the scope of this paper (see e.g. Corning, 2014; Pigliucci, 2009). Here, we focus only on the 
changing conceptualizations of the role of behaviors in evolutionary and developmental biology in relation to our discussion on teleological reasoning in evolution education.

In Darwin's time, nothing concrete was known about the specific mechanisms of variation that created the diversity of phenotypes within and across populations, nor about the specific mechanisms of inheritance that made offspring resemble their parents. Evolutionary theory in the second half of the 20th century has been greatly influenced by the modern synthesis which incorporated insights from molecular biology and genetics into the concept of evolution by natural selection. After all, the discovery of DNA and the mechanism of its inheritance through biological reproduction seemed to make concrete how Darwin's theory of natural selection works.

In the 1950's and 60's, biologists also discussed the possible roles of behavior and learning in evolution, such as behaviors possibly playing significant causal roles in adaptive radiations or as isolating factors in speciation, and that new behaviors may appear before genetic changes in driving evolutionary change (Roe \& Simpson, 1958; referenced by Corning, 2014). Interestingly, in 1970, Mayr also wrote that "Behavior is perhaps the strongest selection pressure operating in the animal kingdom." (Mayr, 1970, p. 388).

Indeed, many concepts in standard evolutionary theory do already incorporate the role of preferences and behaviors in evolutionary change. For example, in sexual selection and social selection, the preferences of others in the social group or population affect the fitness of an organism, and thus evolutionary change of gene-frequencies in a population. In gene-culture coevolution, cultural practices (behaviors, norms, technologies, etc.) can act as selection pressure on genes (Chudek \& Henrich, 2011; Laland et al., 2010). Clearly, in the evolution of some traits, behaviors and preferences (whether consciously held or not) are considered to play an explicit role as causal factors influencing selection pressures.

In recent decades, discussion on the role of behavioral variation, learning and other factors operating during the development of organisms and potentially influencing evolutionary change, has been rekindled. This is because biologists of various sub-disciplines became aware of an increasing number of potential examples of such cases, and evolution science became an increasingly integral part of those sub-disciplines. Proponents of developmental systems biology highlighted that genes by themselves do not lead to phenotypes, but rather genes are one among many causal factors or resources, embedded in contexts rich in other 
resources that are also often causal factors in the development, or reconstruction, of particular phenotypes (Griffiths \& Gray, 1994; Oyama et al., 2001). This basic yet important insight is also being recognized among genetics education researchers (Jamieson \& Radick, 2017). In humans in particular, many observable phenotypes cannot be explained solely by genetic causation, such as language, tool making, literacy, personality, or occurrence of particular diseases. As will be shown below, even causal explanations of the evolution and development of a seemingly "straight forward" phenotype such as upright walking may need to integrate developmental factors beyond genes.

Biologists also highlighted that the proximate-ultimate distinction may obscure the fact that proximate mechanisms are not always simply outcomes of evolution, but can also function as ultimate causes of evolutionary change:

"Standard evolutionary theory can recognise that plastic phenotypes are capable of fine-tuning their adaptations during their development, and may, thereby, affect their fitness. But it struggles to recognize that phenotypic plasticity can ever drive, or co-cause, evolution, through generating innovation, biasing variation, or imposing directionality on evolutionary trajectories. This externalism is a core assumption that causes problems for evolutionary biology and hinders integration of evolution with adjacent disciplines." (Laland et al., 2012).

Similarly, Corning (2014) states that "in practice, proximate and ultimate forms of causation interpenetrate; proximate causes associated with [behavioral choices] may also be responsible for shaping ultimate causes." Developmental biologists similarly began to point out that phenotypic plasticity may reposition the role of genes as sometimes being "followers" rather than drivers of evolutionary change (West-Eberhardt, 1998), a point that had already been made by Mayr in 1958 (cited by Corning, 2014).

Among the concepts that indicate a role of (goal-directed) organism behavior or preferences in driving evolutionary change are niche selection and niche construction (Odling-Smee et al., 2003; Laland \& Sterelny, 2006). According to these concepts, the preferences and behaviors of organisms can change the environmental conditions that the organism (and its descendants) finds itself in, hence changing selection pressures on organisms (and by extension, on genes). While in the 1950's, evolutionary biologists such as Dobzhansky asserted that "Man alone adapts himself, in a large part, by actively or even deliberately changing the environment, and by inventing and creating new environments" (Dobzhansky, 
1955, p. 339), biologists since then observed that in fact, many species actively alter their environments (with no "conscious intention" required), with more or less pronounced influence on evolutionary trajectories. Often cited examples are animals building nests and burrows or burying eggs, beavers building dams, ants cultivating fungi in gardens, animals preferring to forage for particular food sources in their environment, and earthworms loosening the soil thus influencing their environment and the environment that their offspring find themselves in. The behavioral choices organisms make, such as habitat choices and dietary choices, may be important initiators of adaptation of organisms to novel environments/niches, including currently observable adaptations to climate change (e.g. Tombre et al., 2019), as well as responsible for major macroevolutionary adaptive radiation and speciation (e.g. Badyaev, 2009; Dukas, 2013; Moczek et al., 2011; Odling-Smee et al., 2003; Pfennig et al., 2010; Scoville \& Pfrender, 2010; Snell-Rood, 2013). Humans are often considered the prime niche constructors, as our cultural behaviors have become the dominant force shaping our social and natural environments, which in turn provided selection pressure on human traits (Kendal, Tehrani, \& Odling-Smee, 2011; O’Brien \& Laland, 2012; Zeder, 2016).

In concluding this review section, we argue that these developments in evolutionary and developmental biology point to opportunities to tackle a number of misconceptions in evolution education, including the question of how to deal with variations of seemingly teleological reasoning in students, particularly the reference to "need" and other proximate factors.

As the continued debate in evolution education shows, it may be profitable to take on these perspectives because they may allow educators to explicitly link students' everyday experience of proximate needs, goal-directed behaviors and preferences to scientific conceptions of evolutionary change. When educators focus mainly on genes and gene-environment interactions when treating the evolution of traits, it may lead to the abstracting out of "all the biology in-between" (Laland et al., 2012), that is, abstracting out the interactions between environments, behavior, cognition, bodies, brains and genes at multiple levels of organization and different time scales. This may be a short-cut that precisely creates intentional or teleological reasoning and other common learning difficulties in evolution education, or that creates difficulty in distinguishing between appropriate vs. inappropriate reasoning styles of students. It is largely this "biology in-between", that students and all humans know from their everyday experience, whereas genes and wider 
population-level dynamics remain more abstract. Students, as biological organisms, simply experience various needs, and their own behavioral responses to such needs ("I need to drink some water", "I need to go to the bathroom"), in their everyday lives. Furthermore, this "biology in-between" is what students also learn about in other topics within the biology curriculum - ecological relationships, niches, optimum conditions, structure and function, animal behavior, nervous systems, learning, etc. Is it possible that students bring that understanding to the table when asked to talk about the causes of traits, but they simply haven't been given explicit tools to link their understanding of organism behavior, morphology and ecology to evolutionary change? Additionally, asserting that, across the board, behaviors and preferences of organisms do not have a role in evolutionary explanations of traits, leads to confusion when treating standard concepts in evolutionary theory such as sexual and social selection, a point also raised by Varella (2018).

To our knowledge, these perspectives on the role of proximate mechanisms in evolutionary change and resulting teaching opportunities currently appear to not be part of the discussion in the evolution education literature. In this regard, it is worth noting that in a review by Ziadie \& Andrews (2018) on Pedagogical Content Knowledge (PCK) about teaching concepts and topics in evolution, the authors identified no peer-reviewed studies that explored PCK elements for secondary education around the topic of evolution of behavior. Hence, there also appear to be currently no tools to support educators and students in being explicit and specific about the causal roles of behaviors and preferences, as well as genetic mutations and the mechanism of natural selection, in the evolution of particular traits.

Thus, specific teaching tools may help in closing this gap. Such tools may address, among others, the points raised by Gouvea \& Simon (2018), Louca et al. (2004) and Ojalehto et al. (2013), namely that students may be explaining biological phenomena by referring to valid ecological relationships and functions that are then wrongly interpreted as problematic teleological reasoning. In the next section, we propose the use of causal mapping as such a specific teaching tool. 


\section{Causal mapping for teaching behavior as selection}

\section{pressure}

In this section, we argue that causal mapping can be a potential classroom tool to help students and teachers to construct and reflect on causal frameworks that link organism behaviors, bodies, genes and environment in a way that is congruent with biological thinking, and allows student thinking to be made visible to themselves and teachers. Lombrozo (2009) and Lombrozo \& Gwynne (2014) used a narrative form of such causal chains that link a proximate mechanism for a trait and the ecological function of that trait. Here, we show how causal maps can be used to visualize such linkages between proximate mechanisms, functions, and natural selection.

Causal maps are a tool of reflection, inquiry, synthesis and discussion in evolutionary science to disentangle and grasp the complex nature of causal relationships during the evolution of particular biological phenomena, particularly in evolutionary anthropology (e.g. Anton \& Snodgrass, 2012; Chudek \& Henrich, 2011; Coward \& Grove, 2011; Koops et al., 2014; Laland et al., 2011; Whiten \& Erdal, 2012). Causal maps are also used in biology education, e.g. to visualize interactions between species in an ecosystem. Jamieson \& Radick (2017) used causal mapping in a genetics course to highlight the complex relationships between multiple causal factors (including genes, developmental factors, behaviors) influencing each other and a focal phenotype such as cardiovascular disease. However, a content analysis of the human evolution section in 15 German high school biology textbooks (spanning grades, states, and publishers) revealed that only three textbooks used causal maps to depict a more complex nature of causality in human evolution (unpublished data). Among these causal maps, the nature of the causal arrows used is not further elaborated to teachers or students, posing the problem that this might invite teleological conceptions about change (e.g. Baack et al., 2016, p. 482, 493). Also, a popular US biology textbook section on primate (including human) evolution contained no causal explanations at all (unpublished data).

In causal maps, traits, conditions, species or other factors are linked by arrows that mark some kind of causal relationship (e.g. X leads to, changes, or influences Y; fig. 1a). Causal relationships can be of different nature. The concrete nature of a causal relationship can be 
specified if it is known or presumed, or not if it is subject to debate and reflection. For example, "is consumed by" is a commonly used causal link used in causal maps of food networks (with the specific mode of consumption as a still more fine-grained causal mechanism of energetic and nutrient flow within an ecosystem). Alternatively, links categorized as merely "influences" can drive classroom discussions about the range of potential specific mechanisms.

a

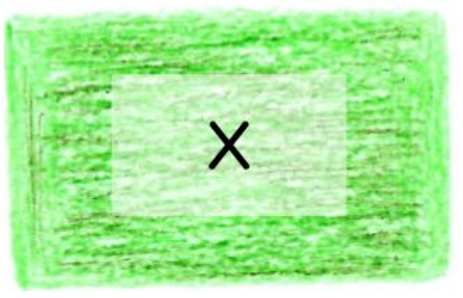

influences, changes, leads to ...
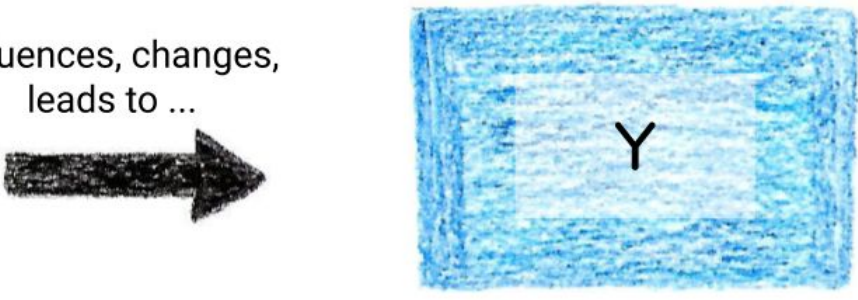

b

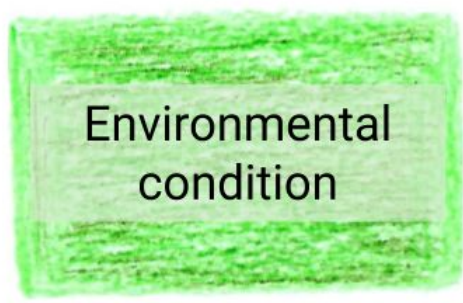

favors the natural selection of...

Fig. 1: Key elements of causal maps - nodes and arrows (a); an example of a specific causal relationship operating in the natural selection of traits (b).

"Natural selection" is a kind of causal relationship in which a condition "selects for" a trait, meaning that it favors an increase in trait frequency in the population and on a phylogenetic time scale due to differential survival and reproduction under those specific conditions (fig. 1b). Environmental factors or other organism traits that enable, facilitate or favor the development or expression of a particular trait mark another kind of causal relationship operating on the level of the individual and on a developmental time scale. Organisms have many different phenotypic and genotypic traits (behavior, morphology, physiology, cognition, genes), and these interact and influence each other in development and evolution, leading to 
trade-offs in the optimization of traits, or causally interdependent "trait packages" that are more or less functionally integrated and selected together.

In this regard, it is important to emphasize that not all traits are caused in the same way (fig. 2). Sometimes a chance genetic mutation, creating a particular phenotype that provides survival advantages in a particular environment regardless of behavior, can be sufficient to explain the development, function, and resulting natural selection of a phenotypic trait (fig. 2a). Sometimes, however, organism behavior (or other proximate, developmental factors) also has a causal role, particularly when considering morphological characteristics that provide a function in relation to certain behaviors such as feeding, mating or locomotion. In such cases, morphological features such as beak size, neck length or shape of the spine often do not have any consequences for natural selection in isolation, but their functions are tightly connected to an organism's behavior (fig. 2b). Particularly in human evolution, topics and concepts such as upright walking, meat-based diet, tool-making, language, (self-)domestication, and gene-culture coevolution cannot be explained by referring to chance genetic mutations alone, and this might invite confusion or incoherence when the topic of human evolution needs to be treated under a generalized framework of evolution.

Furthermore, causal maps may help put the role of genes in a larger developmental context, in line with perspectives from developmental systems biology (Oyama et al., 2001). For example, Jamieson \& Radick (2017) designed an alternative genetics course that emphasized developmental processes rather than transmission, and that emphasized phrases such as "gene(s) involved in" rather than "gene(s) for". Results indicate that these modifications may have the potential to alleviate notions of genetic determinism or essentialism, another set of well-known student misconceptions in biology education. 
a
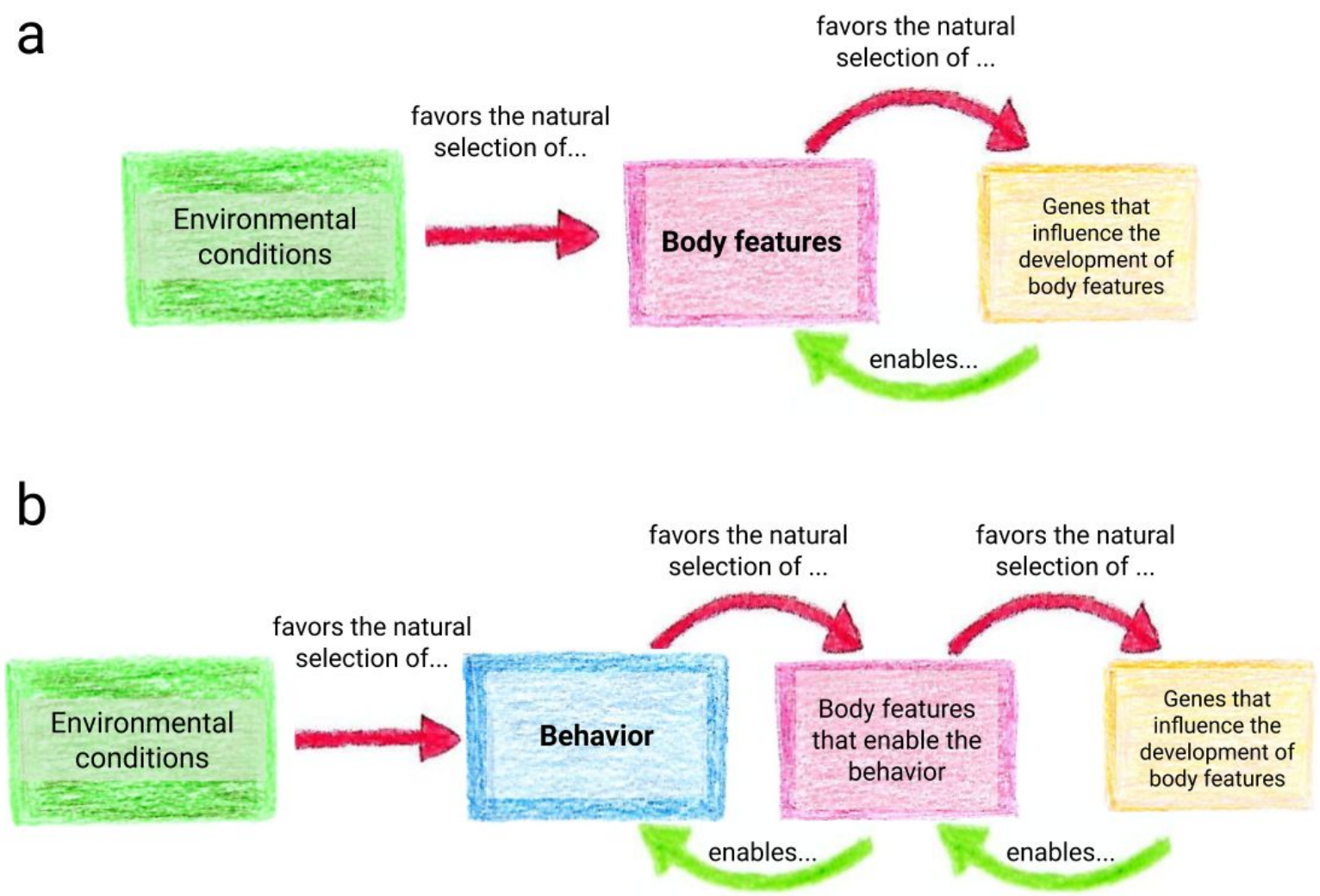

Fig. 2. Hypothetical examples of causal maps in which behavior may not have an important mediating role (a), and in which behavior has an important mediating role (b) in the evolution and development of a trait complex.

Of importance for the purpose of this paper is the fact that the directed causal relationship "favors natural selection of" explicitly links "need" or "function" to a causal mechanism of population-level change: if an organism needs or requires a particular trait, because it functions to enhance survival and reproduction (or in other words, to fulfill a survival and/or reproduction need) relative to alternatives under the given condition (the starting point of the arrow), we can say that there is "selection pressure" on those trait variants that are able to fulfill those needs better than other trait variants, thus those trait variants are likely to become more common in the population through the mechanism of natural selection. These conceptions on the role of need are in line with how some biologists explicitly consider the concept of need in relation to selection pressures within an organism's niche (e.g. Aunger \& Curtis, 2008; Fuentes, 2019; cited above).

In the process of constructing or reflecting on such causal maps, the specific causal mechanism of natural selection, which is a kind of sorting mechanism that operates on the 
level of the population, can (and should) be elaborated with the help of other teaching tools that target population thinking in order to convey the role of the other important core concepts of evolution by natural selection, namely variation, differential survival and reproduction due to trait variation, and inheritance (Andrews et al., 2011; Nehm et al., 2010; Petrosino et al, 2015). These concepts are likely foundational pre-requisites to productive engagement with causal maps of human evolution. To this aim, we developed a "Natural selection worksheet" that allows students to calculate and graph the change in trait frequencies in a population due to variation, differential reproduction and inheritance (see classroom intervention below and supplemental materials file 1 and 2). The resulting graph of the changes of trait frequencies in a population over time can serve as an icon to depict the population-level mechanism of natural selection (fig. 3).

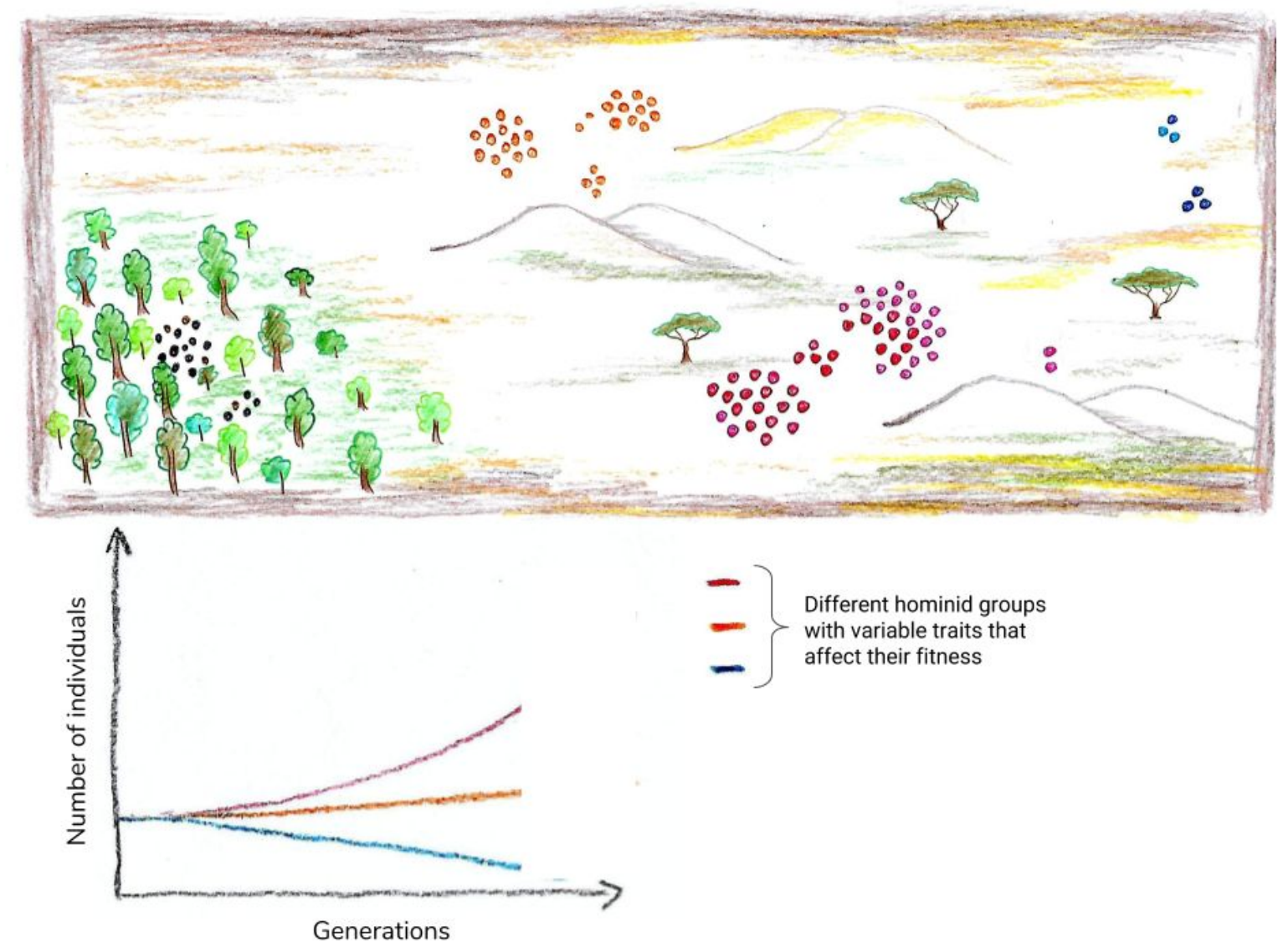

Fig. 3. Schematic drawings and population change graphs which can be reconstructed on classroom chalkboards while engaging students in discussion about variation in populations and selection processes acting on this variation.

It is beyond the scope of this paper to address the wider discussion in biology about the generalized nature of "variation" and "inheritance", beyond genetic variation and inheritance 
(see e.g. Jablonka \& Lamb, 2005; Laland et al., 2015; Mesoudi, 2011; Odling-Smee \& Laland, 2011). However, as the discussion in the previous section indicated, behavioral variation is increasingly considered by biologists to be a causal factor in evolutionary change. Causal maps that relate behaviors, body features and genes can help student reflection on this issue, namely by drawing attention to the fact that without (more or less random) variation in the population and without an inheritance mechanism for that variation, a factor cannot ultimately contribute to population-level changes due to natural selection (see example section on upright walking below).

Thus, it would not necessarily be an instance of unscientific "teleological" reasoning to say that a trait exists because an organism (and its ancestors) has needed it or because it fulfills an important function for the organism (with past natural selection implied as the causal mechanism for the existence of that trait), rather this would reflect teleonomic reasoning (Corning, 2014). Conversely, if a factor affects the natural selection or development of a trait in an organism, there is not necessarily strong selection on that factor because of this causal role, and hence in that case the factor cannot be said to exist because of its function for that organism - it simply exists and happens to affect the organism and/or the population in some way, or has a helpful function for the organism. The latter case relates to the relational-deictic reasoning style that, according to Ojalehto at al., 2013, may be an instance of correct reasoning about ecological relationships. Causal maps can help students and teachers see and represent the differences between such causal relationships. This distinction also helps to visualize important concepts in biology. For example, biologists distinguish between "cue" and "signal" based on whether a factor has undergone selection because of its information function to an organism (then it is called signal), or not (then it is called cue; Hasson, 2000; Maynard Smith \& Harper, 2003; fig. 4), and coevolution is a term to describe such instances in which natural selection between two or more species or factors "goes both ways". In this regard, Thompson (2010) argued for the importance of integrating concepts in coevolution into evolution education, and used causal maps to depict selection arising from the interactions between species. 
a

Information in the biotic and abiotic environment

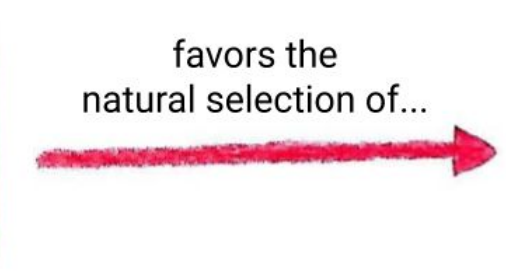

favors the natural selection of...

favors the

natural selection of...

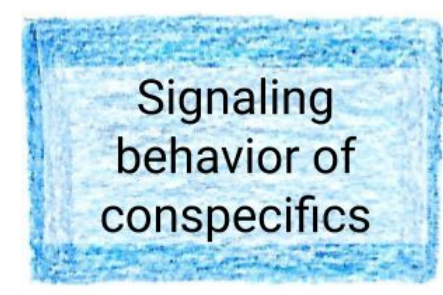

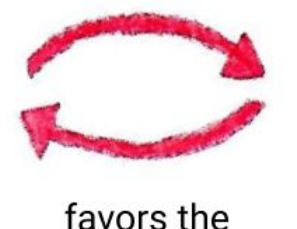

natural selection of...
Traits involved

in adaptive

response to cue

Fig. 4. Example of how causal maps can help differentiate between the instances in which natural selection is a causal mechanism for the existence of a factor or trait, and instances in which it is not, using the example of the difference between "cue" and "signal". a) an abiotic (such as seasonal changes in day length) or biotic environmental factor (such as the rustling sound made by a prey animal) provides selection pressure for an adaptive response. The environmental factor has not been selected for that function to the organism, it simply exists. However, from the perspective of the organism, it has the function of eliciting a response - it is a cue. b) a signaling behavior of a conspecific (such as an alarm call) provides selection pressure on other conspecifics for an adaptive response. The adaptive response requires the signaling behavior of conspecifics, which can come under selection because of that function.

Furthermore, causal relationships between several factors can interact and lead to positive or negative feedback, thus reinforcing (positive feedback) or buffering (negative feedback) the degree of change in individuals, populations, and ecosystems, leading to the decentralized emergence of phenotypes, adaptations, or ecosystem-level properties. Particularly during human evolution, positive feedback between several traits and between traits and the (constructed social, natural, cultural) environment have lead to the 
accelerating rate of change in human brain, behavior, cognition and culture, often also affecting genes. Causal maps can visualize this complex nature of evolving systems, and may help foster a more decentralized mindset or emergent property schema about the nature of natural selection (Cooper, 2017; Petrosino et al., 2015; Xu \& Chi, 2016).

Because of these educational potentials, we have developed a teaching toolkit for causal mapping, specifically for the context of human evolution (fig. 1-3, 5), which allows educators to integrate these perspectives from evolutionary developmental biology and systems thinking. It can facilitate reflection on the specific causal relationships between (socio-cultural and biophysical) environment, behaviors, bodies, brains and genes (fig. 5), and how interactions between these may lead to changes in trait frequencies on the population level over time. The educational design and classroom implementation process will be elaborated further below. In the following section, we show how causal maps may help in reflecting on the evolution of human traits, with a scaffolded example of the evolution of upright walking.

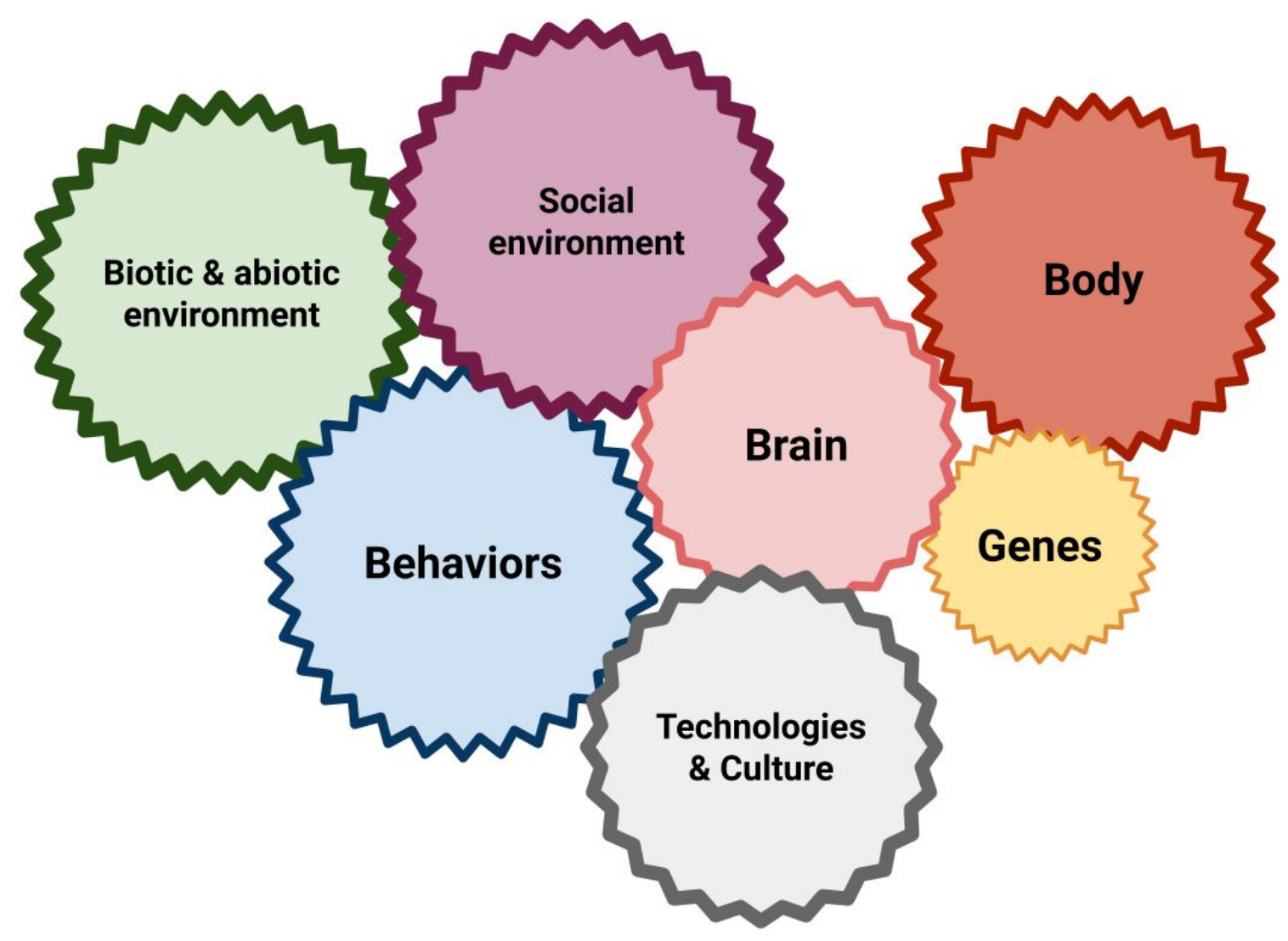

Fig. 5: Causal domains of abiotic and biotic environment, social environment, technologies and cultural knowledge (especially in the case of human evolution), behaviors (including cognition), body features, brains and genes help sort the different causes possibly involved 
in the evolution and development of traits (while being clear that there are not necessarily strict boundaries between them). How do they interact to shape the evolution and development of traits and environments?.

\section{Example: Evolution of upright walking}

The evolution of upright walking is, quite literally, an icon of evolution itself (Werth, 2012; fig. 6), a key element of popular narratives about the origins of our species. In this way, the evolution of upright walking is deeply linked on a conceptual level with the evolution of our human cognitive and cultural capacities (indeed it is the act of upright walking that, in some ways, freed our hands for gestural communication and tool use). It may well seem to students that human intentions and purposes for upright locomotion drove the evolution of this trait in our species. For these reasons, evolution educators and students may benefit by reflecting on the causes and consequences of the linked behavioral-morphological traits that enable our now obligatory upright posture. While upright walking is already a classical theme in human evolution classrooms, and many resources and publications already exist for educators (e.g. Kingdon, 2003; Smithsonian Institution, 2019), this section aims to highlight how the use of causal maps may serve as an additional tool to help integrate these existing perspectives and resources with further considerations from evolutionary anthropology.

How did our species evolve the behavioral trait of habitual upright walking? We of course have to view this question in connection with the evolution of morphological features (e.g. position of the foramen magnum, shape of the spine and pelvis, and the length of arms, legs and toes) that favor this behavior, as well as genes that favor the development of these body features. What role might behaviors and preferences as well as genetic mutations have played in the evolution of these traits? 

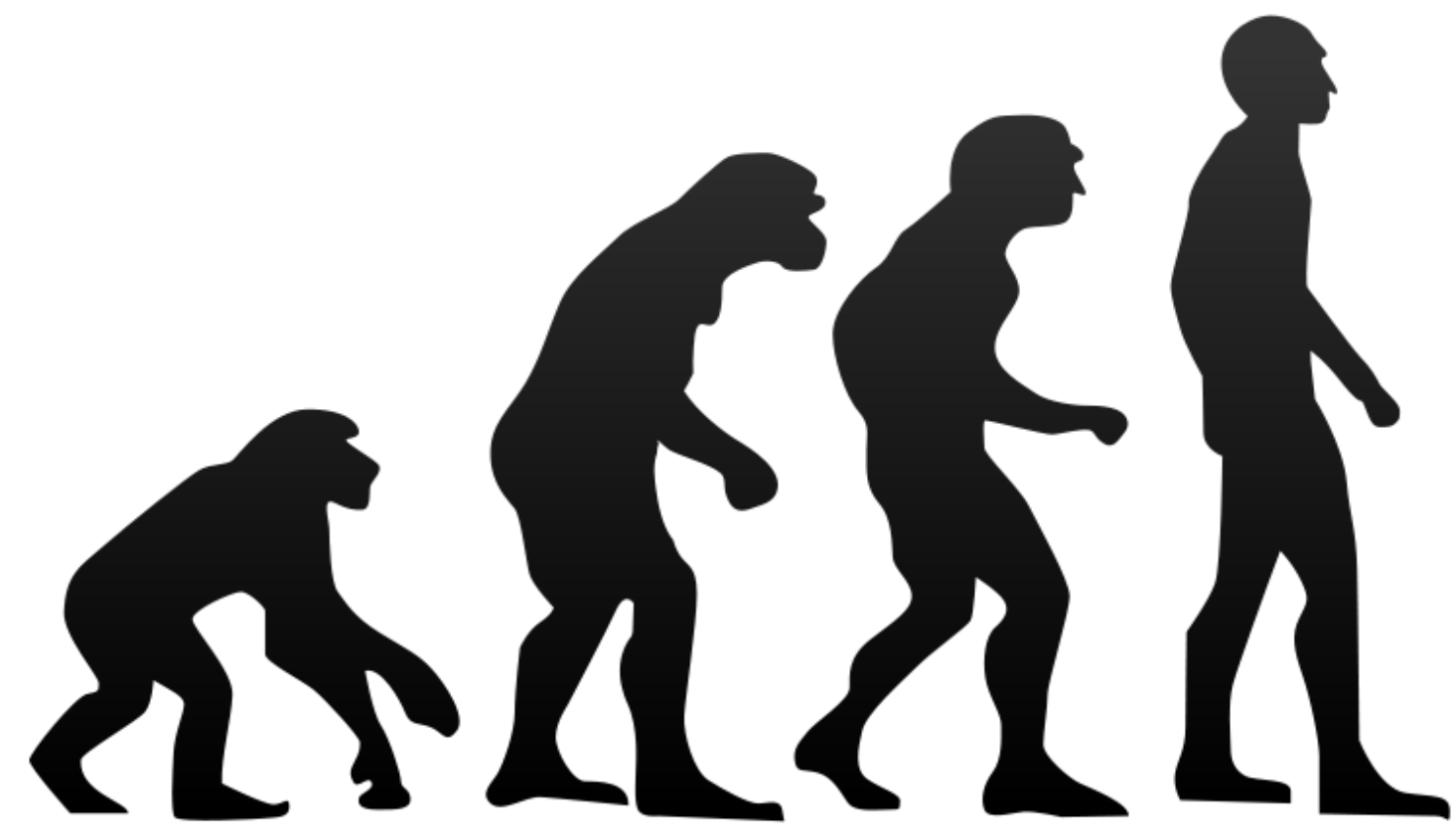

Fig 6. "March of Progress", an icon of evolution often associated with teleological, intentional, or progression-based conceptions of human evolution. Image source: Tkgd2007 (2008; CC-BY-SA 3.0).

An important research paradigm for anthropologists trying to understand the nature of causal relationships during human evolution is the comparative method - comparing the traits and causal factors at play in the observable behaviors of primate relatives with those that might have been at play in the evolution of our hominid line (using archeological and paleontological data). This allows us to directly observe some important proximate mechanisms between environment, behavior and cognition of primates, and link them to possible outcomes over evolutionary timescales.

Anthropologists have been observing chimpanzee locomotive behavior under different habitat conditions in Guinea, which are marked by shrinking forested areas, a mosaic of vegetation and agricultural land (Carvalho et al., 2012). They observed that chimpanzees engaged in bipedal walking four times more often in habitats where there was low density of preferred food items, compared to habitats where valued food items were abundant or where food items were less valued. Furthermore, chimpanzees carried more than twice as many items (food as well as tools) when walking bipedally, using hands, mouth and feet, compared to other modes of locomotion (fig. 7). To anthropologists, these observations of 
chimpanzee behavior under environmental conditions that may resemble those faced by our ancestors, serve as an indication or model to think about the natural selection of upright walking in our ancestors. Clearly, one can say that chimpanzee preferences (for certain food items, for gathering as many of them as possible, and for consuming them in a safe place with low competition from conspecifics) and chimpanzee behavior (bipedal walking in order to - because it allows to - carry as many valued food items as possible) play a role in the expression of the phenotype of upright walking behavior. However, the chimpanzee does not engage in the behavior of upright walking in order to evolve a different body structure, his goal is merely on the proximate level (get tasty food, consume it in a safe place).

Furthermore, this (goal-driven) behavior alone does not necessarily lead to population-level natural selection of body features that enhance the expression of this behavior. It depends on the degree to which this behavior has consequences for survival and reproduction under the given environmental conditions.
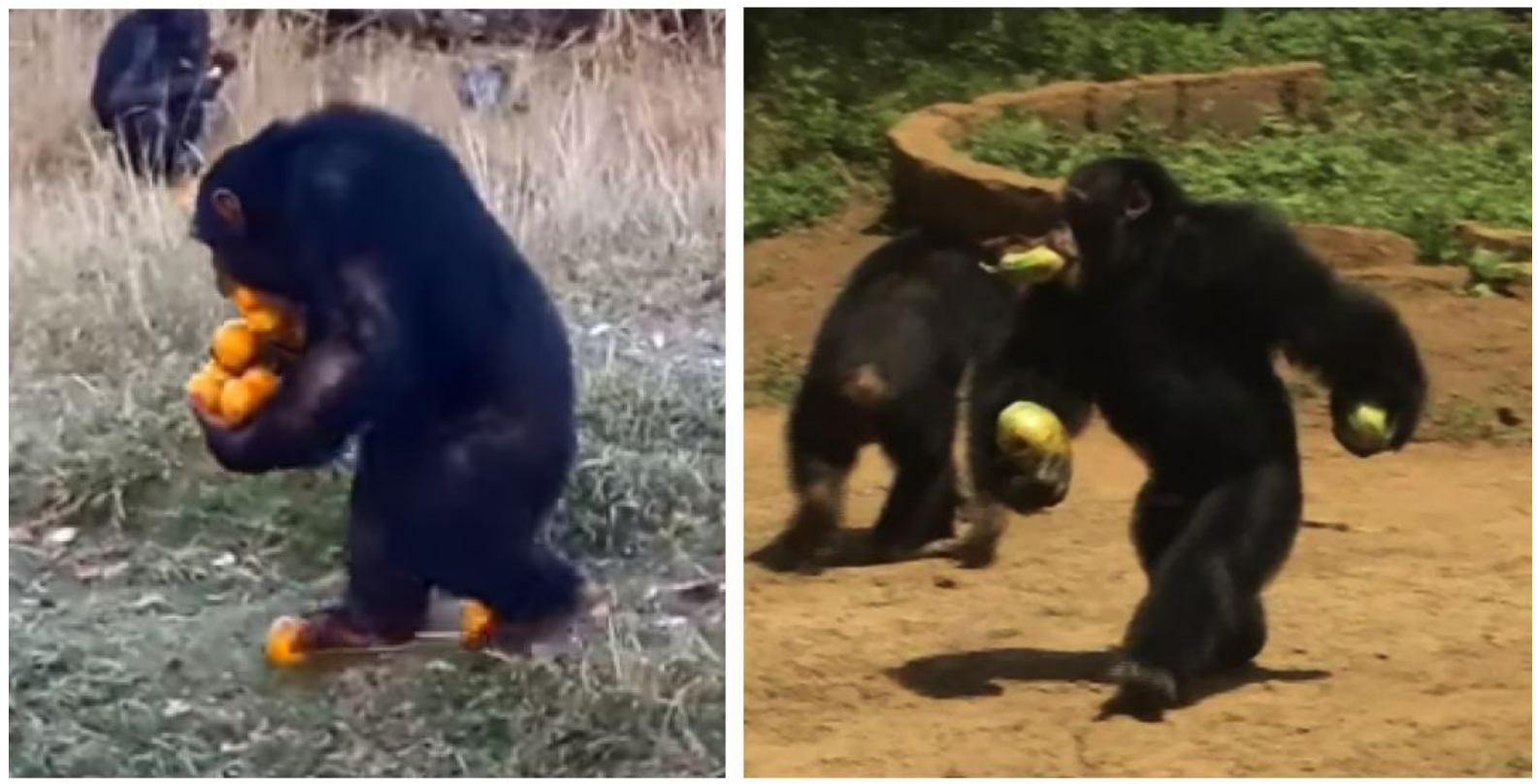

Fig. 7: Images of chimpanzees walking upright, carrying food items. Why does the chimp walk upright? Does his behavior improve his chances of survival and reproduction under the current conditions, compared to the individuals around him who do not engage in this behavior? Does his behavior change his body, or his genes? Sources: Carvalho et al. (2012, Figure 1B, used with permission); LAFFTRIP Videos (2016).

Thus, observing chimpanzees that walk upright under certain conditions, and often with a clear goal (e.g. carrying food items to a safe place; fig. 7), can be a narrative teaching tool 
for teachers and students to think more explicitly about the causal chain that, under specific conditions, may eventually lead to a change in the frequency of body features and genes enabling the behavior of upright walking in a population. Fig. 8 shows how a causal map can be constructed and used to discuss and reflect on the factors and causal relationships that may be at play in a population of chimpanzees in which the environment induces upright walking, but may currently not provide strong selection pressure for this behavior, thus not leading to changes of bodies and genes on the level of the population. Specific reflection questions can probe for student understanding of the causal role of each factor (environment, behavior, body, genes), including the role of function and heritable variation, for example:

- Could the behavior of upright walking in a population alone (possibly similar to the one observed in the chimpanzee), without a pronounced relative advantage for survival and reproduction, lead to the natural selection of this trait?

- Could the behavior of upright walking alone (possibly similar to the one observed in the chimpanzee), without differences in this ability within the population, lead to the natural selection of body features that facilitate upright walking?

- Could differences in bodily abilities for upright walking lead to the natural selection of these features, even if they were not influenced by genes?

- Could a genetic mutation alone, without the organism carrying out the behavior of upright walking, lead to the natural selection of body features that facilitate upright walking?

Such "What would happen if" questions are known as counterfactuals in the literature on causation and causal reasoning (Pearl \& Mackenzie, 2018), and they are important tools to uncover necessary and sufficient causes for a phenomenon. 

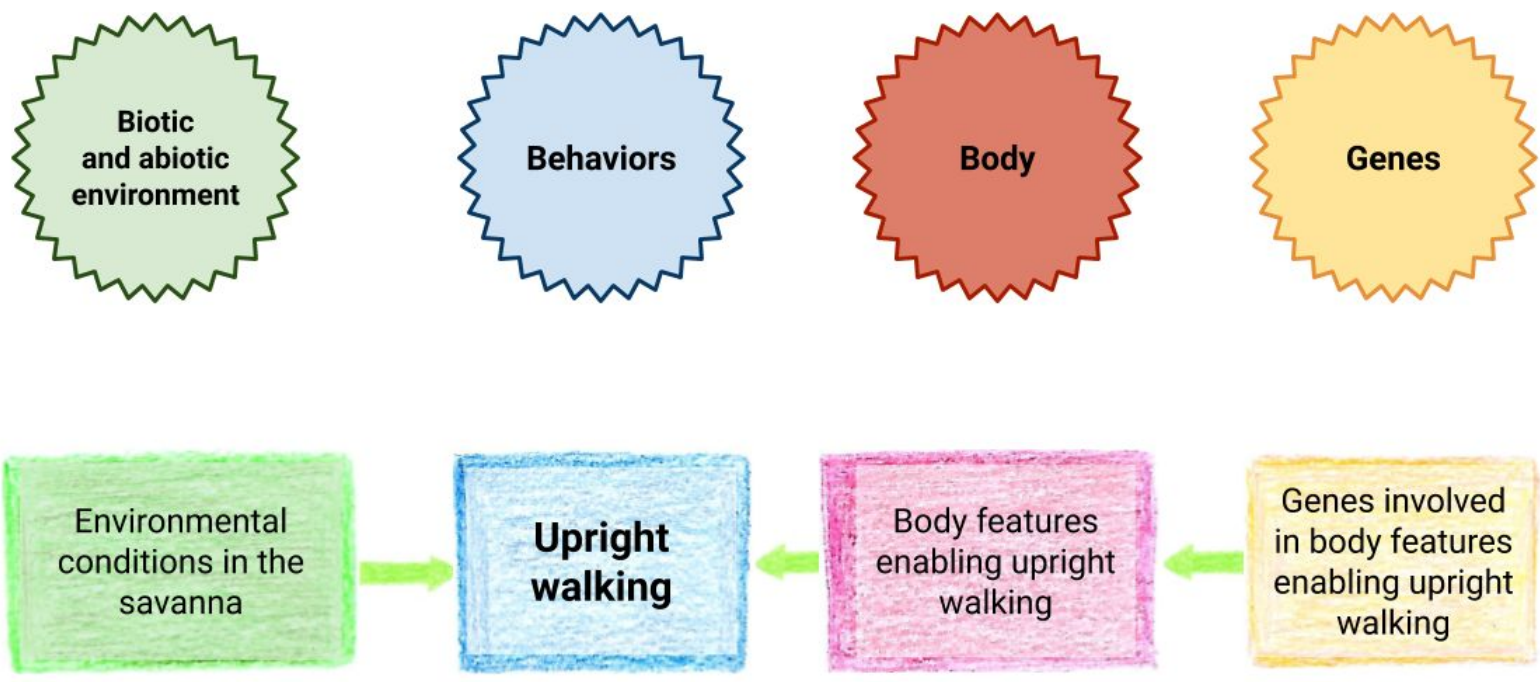

Genes involved in body features enabling upright walking

Enables/allows/facilitates/favors the development of ...

Fig. 8: Causal map of a population of chimpanzees walking upright under certain environmental conditions that elicit this behavior. (1) Environmental conditions may provide more or less strong stimuli for the behavior to be expressed in the population. Assuming that bipedalism does not (yet) have strong consequences on relative fitness of chimpanzees, there would be no significant selection pressure on this behavioral trait, and no selection of other traits favoring this behavior. Current body features of chimpanzees (2), and genes involved in the development of such body features (3), enable the behavior sufficiently well but their variation in the population would not change further through natural selection.

How does this scenario of chimpanzees walking upright compare to the possible scenarios of the evolution of upright walking in our ancestors? Carvalho et al. (2012) note that, over the long term and under prolonged environmental selection pressures, "such carrying of valuable items could act as a strong selection pressure. The energetic intake resulting from resource monopolizing through short bipedal bouts of carrying may eventually select for a gradual anatomical change.", and that "if the environment of early hominins provided similar high value, unpredictable resources at a greater frequency than seen in most of today's chimpanzees, this could reward higher frequencies and/or longer distances of bipedal bouts of carriage, creating a selection pressure for more economical bipedality." (Carvalho et al., 
2012; emphasis added). These quotes highlight how the notion of behavior as selection pressure needs to be employed if we want to understand the evolution of a trait complex such as upright walking (which includes behavioral, morphological, and genetic components).

We can represent this in a causal map by adding these "selection pressures for more economical bipedality" (fig. 9). Under the environmental conditions faced by our ancestors, there was presumably a pronounced selection pressure for the behavior of upright walking, meaning that those engaged in upright walking had a clear fitness advantage over those that did not. The behavior of upright walking would have spread in the population (possibly by a combination of different selection and inheritance mechanisms, such as imitation of others, triggering of the same behavior in individuals independently, and/or differential survival and reproduction). Among those engaging in adaptive instances of upright walking, those with body features enabling them to do so better, or longer, or more efficiently, would have had a further fitness advantage over others. In this regard, studies that evaluate the energetics of chimpanzee and human bipedalism (e.g. Sockol et al., 2007) add important insights into this link of the causal chain, i.e. the role of body features enabling or facilitating upright walking. Among those with body features that improved upright walking abilities, only those whose body features were influenced by their genetic makeup, would have offspring that would have genetically inherited these traits and the resulting fitness advantages. Genes involved in the development of body features that promote upright walking would have spread in the population through differential reproduction and genetic inheritance. Thus, in this causal map of the evolution of upright walking, together with population thinking prompts that highlight the role of population-level variation within each factor, we have explicitly integrated and closed the loop between "need" and "natural selection", as well as between proximate mechanisms (behaviors and preferences in response to environment) and evolutionary consequences. 

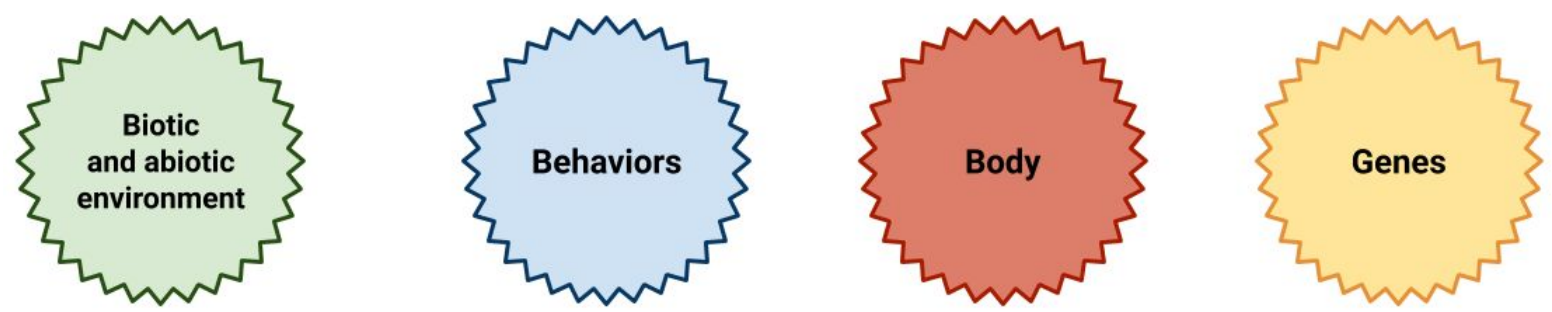

1

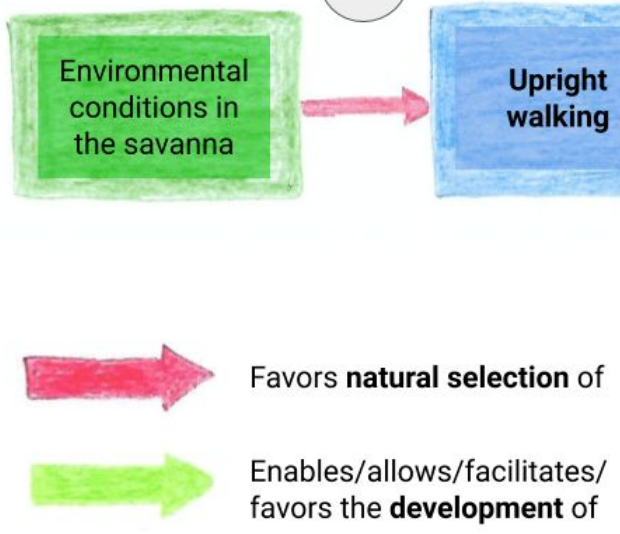

$2 a$

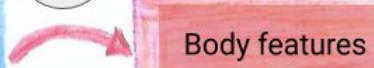
enabling upright walking
$3 a$

Genes involved in body features enabling upright walking

Fig. 9: Causal map of the evolution of upright walking in our hominid line through the interaction of environmental conditions, behaviors, bodies and genes. (1) Environmental conditions provide a selective advantage to the behavior of upright walking. The behavior would become more frequent in the population. (2) Among the population of increasingly habitual bipedalists and with continuing selection pressure, those with body features enabling better or more efficient upright walking, would have had a selective advantage and thus have higher chances of survival and reproduction over others, and those body features would become more frequent in the population. (3) Among those with body features enabling better upright walking, only those whose body features are influenced by genetic makeup, would have offspring who have genetically inherited these traits and the resulting selective advantage. Genes involved in bodies capable of upright walking would become more frequent in the population (through differential reproduction and genetic inheritance).

As a side note to causal mapping, it is important to point out to students that such causal maps of complex biological interactions are never necessarily "complete", but provide a snapshot of theoretically important interactions that we are concerned with in a particular inquiry. In fact, an additional valuable reflection on the development of the phenotype of "upright walking" can be a question about the possible role of social environment. Humans 
do not begin to walk upright soon after they are born. Instead they learn this behavior over the course of their first year (fig. 10).

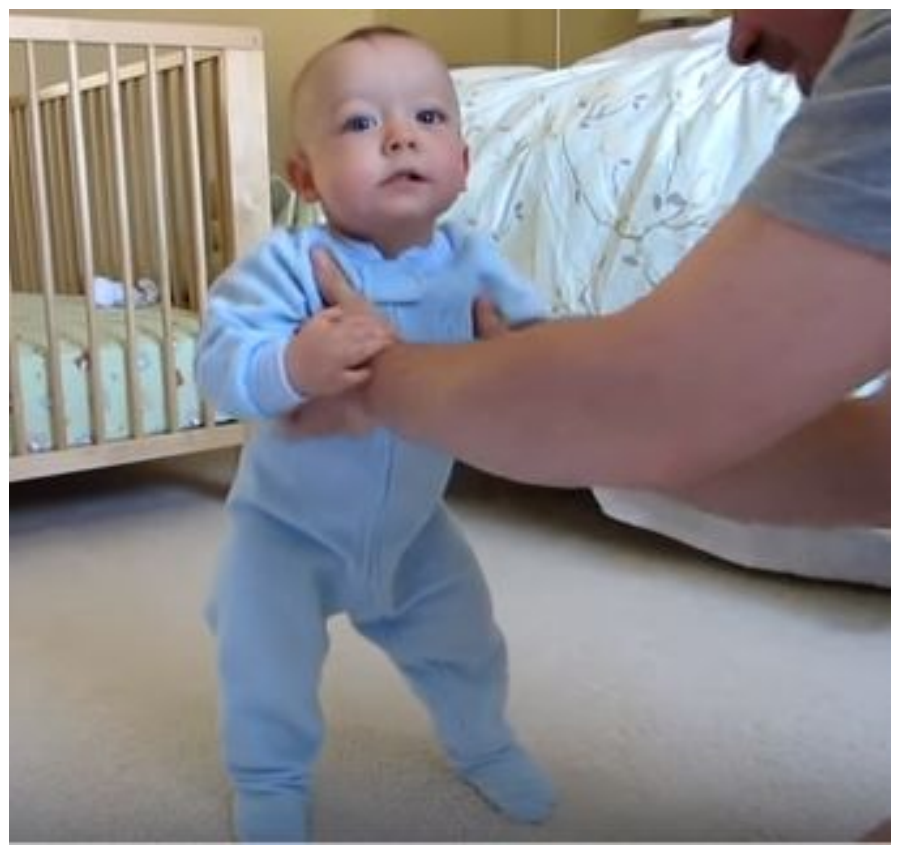

Fig. 10. Videos of human children learning to walk upright can be a valuable tool for reflection on the different resources (beyond genes) that may play a role in the development of the behavioral phenotype of upright walking. Source: rbtha (2012).

What role might the transmission of the behavior by social learning and teaching play in the development of this phenotype? Would a baby learn to walk upright in the same manner, if no other human around him did so, or if no other human was supporting him or cheering him on in his attempts to stand up, thus reinforcing the behavior? We cannot find out by conducting an experiment for ethical reasons, but observing the way that parents and others as well as cultural objects in the environment support the developing human in learning this behavior, can give us a clue that, perhaps the social and cultural environment may indeed play some role in the causation or developmental reconstruction (sensu Oyama et al., 2001) of this phenotype. One opportunity to reflect on the causal role of the socio-cultural environment regarding the development of human locomotion, is provided by the study of child motor skill development across cultures. Studies find that there is substantial cultural variation in the onset of various stages of motor skill, apparently due to "cultural and historical differences in childrearing practices and infants' everyday experiences" (Rachwani et al., in press; see also Karasik et al., 2010). 
Another opportunity to reflect on the causal roles of genes, body structures, brain function, and socio-cultural environment regarding the development of human locomotion is provided by observations of human individuals who have apparently not developed the capacity for walking upright but instead habitually walk on hands and feet, the so-called Uner Tan Syndrome. Scientists debate around the role of genes and other factors in the development of this phenotype, but there seems to be some agreement that it involves complex interactions among a few genetic mutations that influence brain function, constraints and opportunities provided by evolved human body features, as well as factors in the social environment of these individuals (e.g. Humphrey et al., 2005; Shapiro et al., 2014; Tan, 2010; see supplemental material file 5 for classroom discussion ideas on these aspects).

How can we add these additional causal factors, specifically of social environment, into our causal map? Fig. 11 shows the modified causal map to indicate the possible causal role of social environment in facilitating the development of upright walking behavior.

Such explicit considerations of other causal factors beyond genes can support transfer of learning and assessment of student understanding as well as the cultivation of a more decentralized mindset about the emergence of phenotypes (see Jamieson \& Radick, 2017; Oyama et al., 2001). 

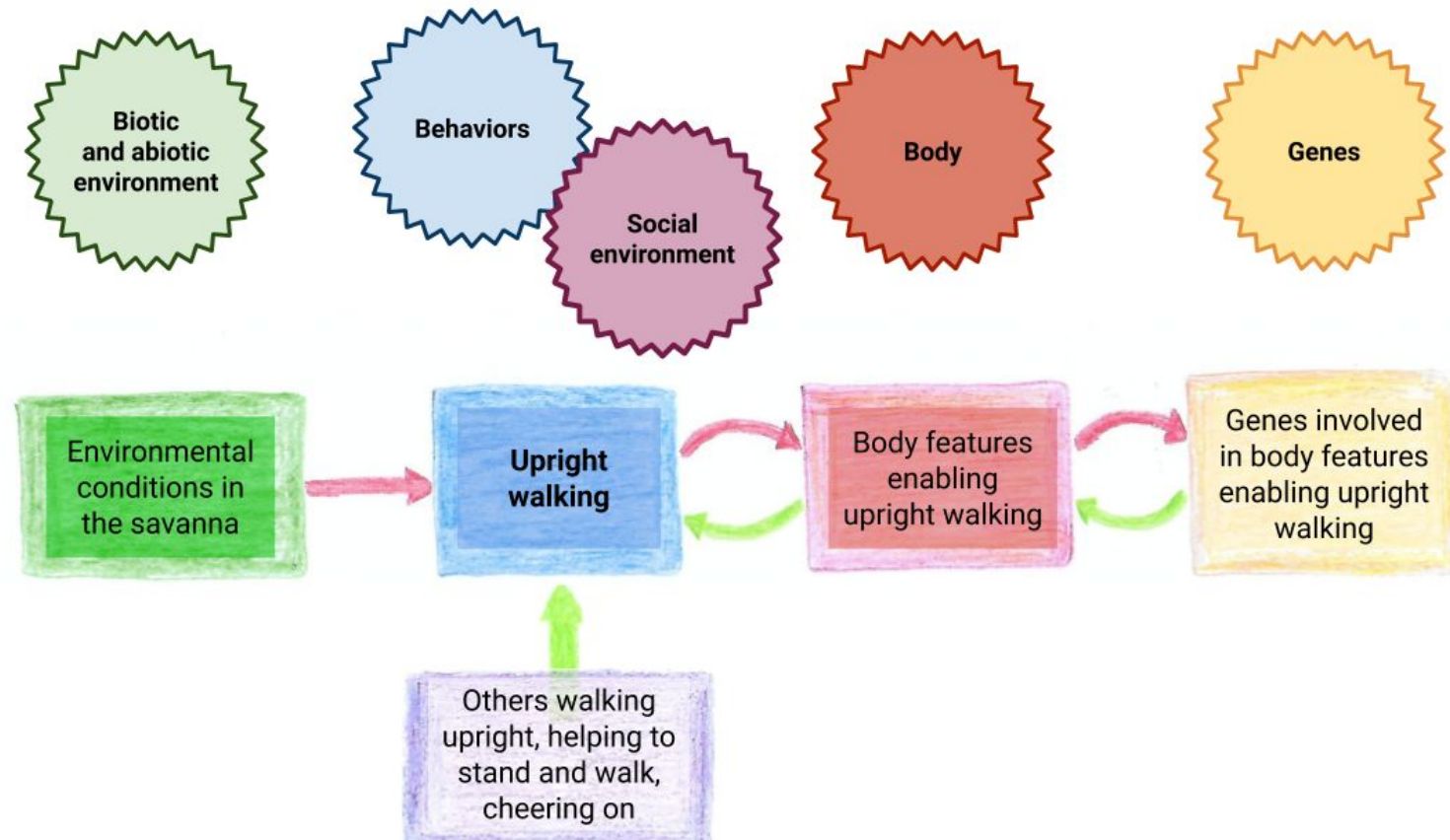

Favors natural selection of

Enables/allows/facilitates/ favors the development of

Fig 11.. Causal map of the evolution and development of the phenotype of upright walking with the additional causal role of social environment.

\section{Causal mapping classroom engagement example}

The causal mapping tool presented in the previous sections was developed and implemented by the authors within the context of a teacher-researcher collaboration in several German biology classes on the topic of human evolution. This intervention was part of an exploratory pilot phase in a long-term design-based implementation research (DBIR; Fishman et al., 2013; Penuel \& Gallagher, 2017) project by the authors (Eirdosh \& Hanisch, 2019). The aim of the project is to develop teaching tools, lesson materials as well as training and guidance for teachers and curriculum coordinators to integrate innovative methods and insights about human evolution and behavior into educational practice across subjects. The aim of the exploratory phase during the school years of 2017/2018 and $2018 / 2019$ was to examine, in close collaboration with a classroom teacher, the opportunities and challenges of using methods and insights of evolutionary anthropology in biology classrooms, with the causal mapping approach presented here as one emergent strategy we explored and refined. 
It is important to note that the educational context that we report on are biology classrooms in Germany, where acceptance of evolution on religious grounds is much less of a concern than, e.g. in parts of the USA. Furthermore, topics such as the evolution of human behavior and culture, including the concept of cultural evolution, are part of the biology high school curriculum. Nonetheless, a review of 15 German high school biology textbooks revealed that methods and concepts of evolutionary anthropology, such as cross-species behavioral experiments and causal maps of trait causation are rarely featured in sections on human evolution. Often, historic chronological accounts of the appearance of traits during human evolution, or rather simplified accounts of how certain traits such as tool use, language and other cultural traits may have evolved, prevail (unpublished data). Thus, educators in Germany continue to face similar challenges as elsewhere in terms of teaching human evolution as congruent with current perspectives in evolutionary anthropology.

\section{Description of the teacher-researcher collaboration and design}

\section{process}

Within the DBIR project, we engaged a 12th grade classroom and two 10th grade classrooms of one high school biology teacher, based on her interest in using innovative content and methods for teaching human evolution. The topics of evolution and human evolution are part of the state-mandated biology curriculum in both 10th and 12th grade. We used observation notes, photos of student and teacher work, as well as audio-recordings and notes of teacher-researcher discussions to document the challenges, opportunities and promising teaching strategies encountered during these interventions. We present here only those insights relevant to the design improvements of the causal mapping toolkit.

\section{First iteration: 12th grade biology class}

The 12th grade classroom was engaged in two $1.5 \mathrm{hr}$ sessions which were taught by the authors at the end of the school year 2017/2018. One of the two sessions was based on a paleoanthropology lab using replica fossils of hominin skulls based on Bayer \& Luberda (2016). In this lab, students measured morphological traits of 13 fossil skull replicas, namely opisthion index, prognathism, and cranial capacity. Changes in these morphological traits can be productively linked to changes in the behavioral traits of upright walking and diet as well as to the trait of brain size, respectively. In the second session we engaged students in 
the analysis and interpretation of measurement results. We constructed a causal map on the board that linked the measured morphological traits to narratives and data about changing environmental conditions and the kinds of behaviors that would provide a selective advantage under these conditions (students were already familiar with concepts in evolution such as fitness and natural selection). After introducing and co-constructing the initial causal map with the evolution of upright walking, meat-based diet, and brain size, we gave students further short-text and worksheet materials that would allow them to expand the causal map by the evolution of further traits, including long-distance running, collective hunting, tool making, prolonged childhood, language, social emotions, social organization, and cumulative culture. Student groups added these elements to the causal map on the board. The instructor pointed out to students the feedback loops that were visible in this causal map, particularly the feedback loop involving brain size (see fig. 13), emphasizing that such feedback loops help us explain some of the rather rapid, exponential changes in human traits during our evolution. After the end of this intervention, some students remarked that they "have never seen it all presented in this big picture like that" and "usually, we just treat every topic in isolation and narrow-mindedly, and here it came all together and we saw how it is all connected."

\section{2nd iteration: 10th grade class}

Based on positive engagement and feedback from students after the 12th grade intervention, the teacher requested to continue the collaboration with two of her 10th grade biology classes in the following school year of 2018/2019. In both classes, the topic of evolution, including human evolution, would be relatively new to students and thus required further lesson design to engage students in foundational concepts such as variation, function, fitness, natural selection, inheritance. One of the two classes was a remedial class transitioning from another school and repeating the 10th grade, and the teacher had relative freedom in deciding which topics should be engaged in biology within the school year. We engaged this remedial class for a total of thirteen $1.5 \mathrm{hr}$ sessions, and the other regular 10th grade classroom for a total of eight $1.5 \mathrm{hr}$ sessions, with most of it taught by the teacher while the authors largely took on observer and advisory roles.

Both classes were engaged in the skull lab in two sessions, including analysis of measurement results, at the beginning of the school year. Following the skull lab, the authors taught the two classes on the evolution of upright walking, referring to one of the skull measurements (Opisthion-Index) and using videos and worksheets (including the videos and 
narratives presented in the previous section on upright walking, see supplemental material file 5). To convey the concept of natural selection, the teacher-researcher team co-developed a worksheet ("Natural selection worksheet", see supplemental materials file 1) in which students calculated and graphed the change in trait frequencies within a hypothetical population, where three trait variants existed that had different outcomes for reproductive success, over the course of 10 generations. Students filled out the worksheet with the example of body features (Opisthion-Index) that facilitate upright walking. Classroom observation and discussion indicated to the teacher and us that students understood and had no problem filling out the worksheet. Future interventions may probe individual student understanding further by using such worksheets as formative and summative assessment tools with different trait examples and further reflection questions about the role of trait variation, trait function in terms of reproductive success, and inheritance, in evolution through natural selection (see supplemental materials file 1).

After this, the teacher-researcher team decided that it would be most productive for the teacher to continue the teaching role, with our guidance and advice in the background. She decided to continue the collaborative teaching on the topic of human evolution in the remedial 10th grade class, while she decided it would be necessary to first teach the subject of genetics to the other 10th grade class (see third iteration).

We provided a range of materials, including videos and worksheets, on evolutionary anthropology research regarding human and primate behavior and cognition, including social temperament and socio-cognitive skills involved in cooperative foraging and tool making, social skills such as communication, social learning and teaching. The teacher chose among our materials the ones that would be most important and engaging to students. However, there was a significant learning curve for the teacher as this approach to teaching about human evolution, such as using comparative behavioral research, was completely new to her.

The teacher decided to have students again complete our "Natural selection worksheet", this time linked to success rate in cooperative foraging (for which traits like social temperament and social cognition were functionally relevant, see supplemental materials file 2 ). This was done to reinforce in students a transferable understanding of the concept of natural selection, namely a mechanism that leads to changes in trait frequencies in a population. 
After five sessions, the teacher decided to let students write a one page essay on the topic "The evolution of social and cognitive skills in the population of our ancestors 2-3 million years ago", as a summary of the material covered in previous lessons. We proposed to the teacher that causal maps (similar to the one introduced in the first iteration in 12th grade) might be helpful to students to visualize and specify the connections between the development and evolution of the different traits that we had covered, and might also be helpful to us teachers to better understand student thinking. We thus modified and developed further materials and instructional techniques around the causal mapping method that would be appropriate for this class, resulting in the causal mapping teaching tools that we present in this paper.

In this context, one of the authors introduced students to the causal mapping method by providing a few concepts and the nature of the causal relations "requires/ favors selection of" and "enables/favors the development of". The initial example given was of environmental conditions selecting for the behavior of meat eating (because of survival advantages under the environmental conditions of the savanna), and the behavior of meat eating selecting for the behavior of tool use (because it enables the extraction of more meat from the environment). The presentation of the causal map was connected with the concept of natural selection by reminding students of the natural selection worksheets and drawing a graph of trait frequency change on the board (see fig. 3). The instructor then guided a classroom discussion by encouraging students to gather on the board further traits that we had covered in previous lessons, and to propose how we might connect them to the causal map. During this discussion, we had the opportunity to gauge students' recollection and understanding of previous materials as well as their understanding of the causal mapping method, including the nature of the different causal relationships.

Students were then asked to work in groups and use the causal mapping method to visually represent their written texts (student essays and causal maps were not collected). Fig. 12 shows the causal map produced by one student group on the board. The rest of the class was then encouraged to comment on the causal map and make corrections if they found any questionable linkages. The initial causal map had 7 conceptually incorrect linkages out of 13 total, with all of these 7 being corrected by the class with minimal input from the teacher. 
Note that while "genes" and "brain" do not appear in this causal map, this does not mean that genes and brain function/organization do not play a causal role in the development of the cognitive and social traits in question, nor that there wasn't selection on genes and brain function/organization in the evolution of these traits. Students can be encouraged to extend the causal map to include the role of brain function, brain organization and/or genes (especially after engaging in materials that point to a genetic signature in the cross-species variation of such traits, or to a change of brain size or brain organization during human evolution), which would again reflect the degree to which they understand the nature of the causal relationships.
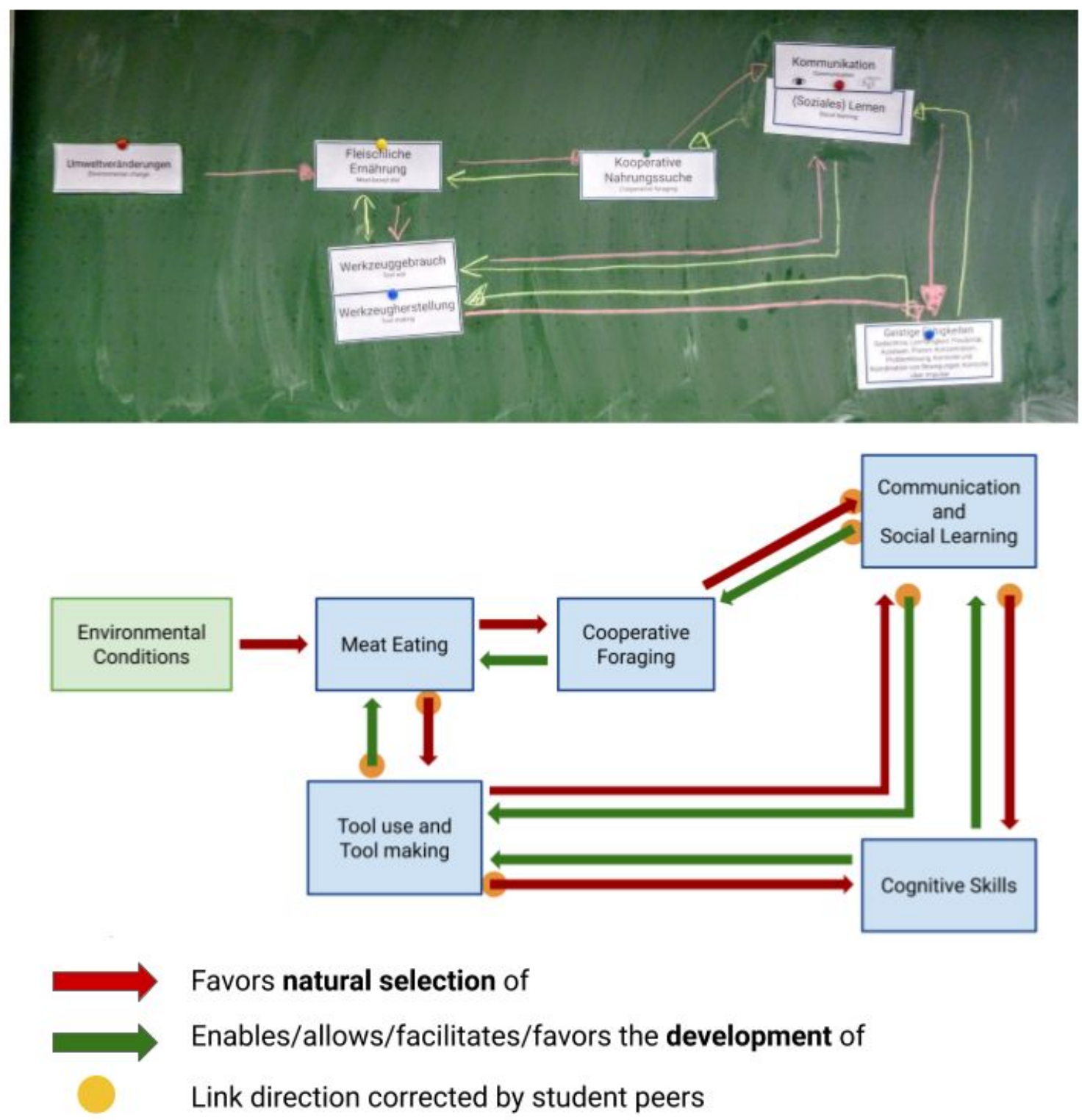

Fig. 12: Students in a 10th grade biology classroom in Germany translate their own essays on causes of early Homo evolution into causal maps which they then present, critique, and 
revise as a class.

\section{3rd iteration: 10th grade class}

The second 10th grade class was engaged in the topic of human evolution for three $1.5 \mathrm{hrs}$ sessions towards the end of the school year, after the teacher mostly taught about genetics for several months (the state curriculum prescribes the topic of genetics to be taught for $50 \%$, evolution for $30 \%$ and human evolution for $20 \%$ of biology lessons within the grade 10 school year). These three sessions were mostly teacher-driven, as the teacher was by now more familiar with the materials and felt confident in choosing the content and methods. She decided that materials about the role of cooperation, teaching and learning in the evolution of our species were the most important concepts to cover in these sessions. She again decided to use the natural selection worksheet, as well as the causal mapping technique in the final lesson.

We created a student hand-out that introduced the causal mapping method by the example of upright walking (see supplemental materials, file 3 ), and we allowed students to read it for five minutes. One of the authors then took on the teacher role and presented the construction of the causal map in a step-by-step fashion on the board in front of the class, again with the example of upright walking (see section on upright walking above). At first, only the red arrows marking "needs/requires/ favors natural selection" were added, with explicit integration of the mechanism of natural selection by reminding students of the natural selection worksheet and using the graph of population change as an icon (fig. 3), linked to the red arrow.

The following discussion, reconstructed from observation notes, highlights how this instruction apparently changed one student's conception about the nature of change through natural selection:

Student A: "So do I have to imagine it like this, like a Homo erectus is standing up all the time, and standing up again and again, and then over time this changes his genes?"

Answers and comments from other students in the class included "No, it's random changes in the genes." One student gave an example that she has no wisdom teeth while everybody else in her family does. 
After a while, student A asked again: "But so the environment leads to the expression of traits?" (still only red arrows from environment to behavior to body to genes were included in the causal map so far)

Teacher: "What do you mean exactly, the environment leads to...?. For behavior, yes, as we also saw with the chimp, behavior change can be induced by the environment to some degree, we and other animals can react to their environment by changing their behavior. But what about body features, how does 'environment change' that? Can we change our body much during our life, or our genes? How does this change happen in a population?"

Student A: “Hm, don't know...”

Teacher points to the icon of the natural selection graph under the red arrow on the board.

Student A: "Oh.... through natural selection..."

The teacher emphasized again that the red arrow "needs, favors the natural selection of" should be interpreted in connection with this sorting mechanism: "In a situation (starting point of the arrow) where an organism needs this trait X (target of the arrow), because it will be beneficial to survival and increase the chances of reproduction, the trait will tend to become more common in the population because of this sorting mechanism of natural selection".

The teacher then added the green arrows denoting the relationship "enables, favors development of" from genes to body, body to behavior. To probe for student understanding, the teacher asked the class: "So can we now add a green arrow also from upright walking behavior to environment?" Students in the class generally shook their heads.

After this introduction of the causal map through the example of upright walking and no further clarification questions from students, students formed groups and were asked to create similar causal maps relating a number of possible concepts (traits) that were covered in the previous two sessions and presented on the board: environmental conditions of the savanna, upright walking, meat-based diet, cooperative foraging, tool use/tool making, social temperament, social cognition, social learning and teaching, communication, cognitive skills, brain size, body features enabling a trait, and genes involved in the development of a trait. 
Fig. 13 shows a possible causal map produced by the authors as a model that links all of these traits. Note the feedback loops that can be pointed out to students in such as map, such as the ones involving brain size. Note also that there are still many more conceptually correct causal arrows that could be added to this map. Furthermore, the question whether a certain trait has undergone selection because of a specific function (e.g. whether upright walking was selected because it facilitated tool use, in addition to other functions) is an empirical one that is often difficult to investigate precisely because of the complex nature of causation during evolution, and causal maps can help clarify and reflect on this fact (e.g., should we add a natural selection arrow or not, from tool use to upright walking?, see fig. 13). We argue that it is productive to discuss with students the complexity of finding answers to these questions, as these are precisely the questions that evolutionary biologists engage. The function of the nose in holding glasses is an often cited example in which it is easier to see that the nose has not been selected for this function, thus does not exist because of this function. However, sometimes we do not know enough to decide whether a trait exists because of a particular function (i.e. has been selected because of it), while a particular function may nonetheless be of biological importance to an organism. This issue relates to the problems around teleological reasoning pointed out previously, namely that student reasoning about ecological relationships involving functions may reflect valid biological reasoning, rather than an instance of faulty teleology (Ojalehto et al., 2013). 


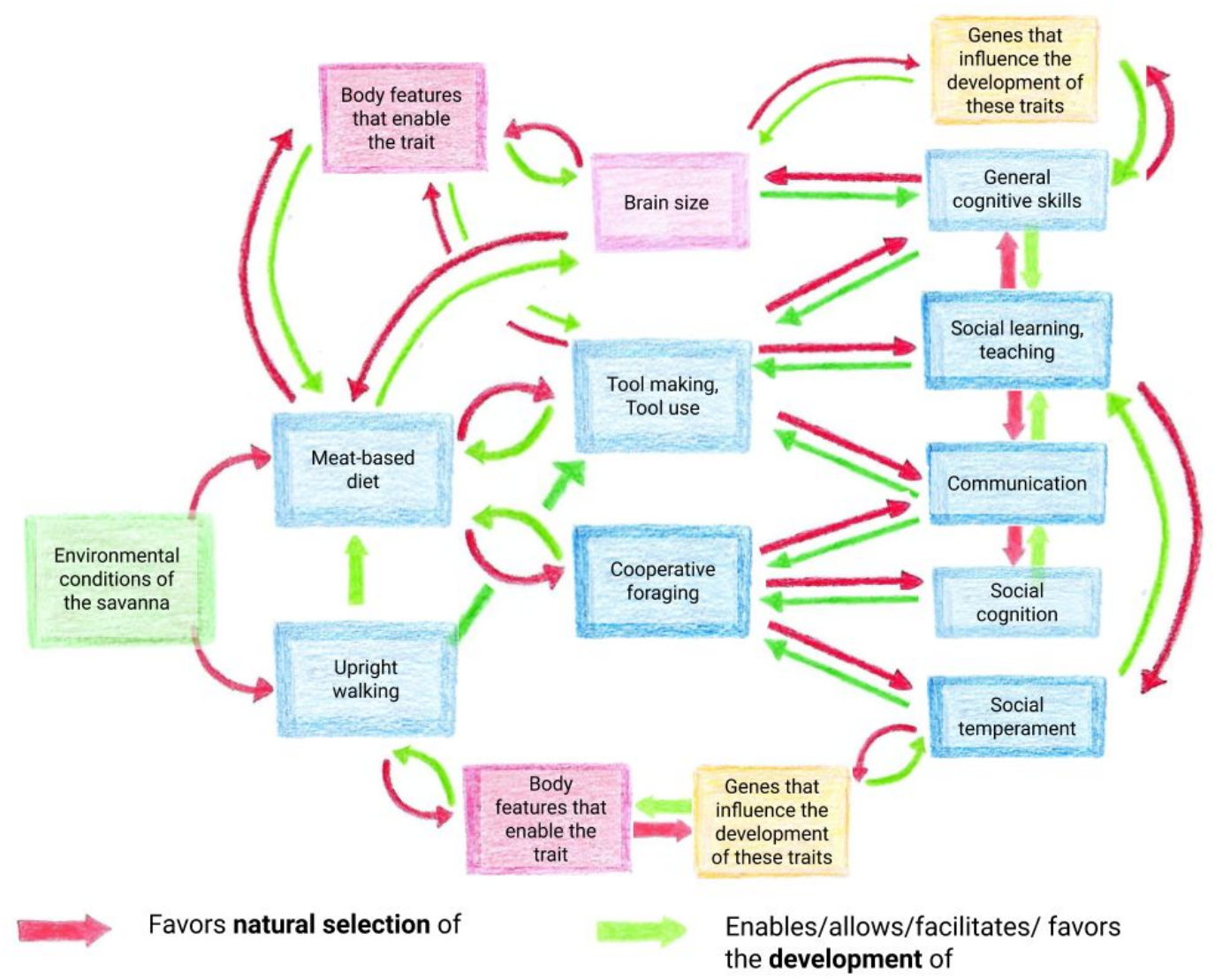

Fig. 13: Causal map showing some of the possible causal linkages that lead to the natural selection and development of various traits during the evolution of the Homo lineage. Note the feedback loop between meat-based diet, tool making, cognition, and brain size.

Beside these possible complexities, certain linkages in such causal maps can be considered implausible, such as "meat-based diet enables tool use" or "cooperative foraging enables social cognition", or "communication requires cooperative foraging". Hence, while causal maps reflect a necessary degree of speculation, critical reflection on explicit causal linkages can drive discourse on these issues.

Assessment of student causal maps can draw on methods developed for the use and assessment of general concept mapping techniques in education (e.g. Cañas, Novak, \& González, 2004; Lie \& Lee, 2013; Van Zele, Lenaerts, \& Wieme, 2004). As this causal mapping intervention was only carried out within a 45 minute session, including an introduction to the causal mapping method, and was done in groups, we only present here a general analysis of the variation of student causal maps produced. Of the ten student groups, four groups used 11-12 concepts (traits), four groups used 9 concepts, and two groups used 6-7 concepts. The concept of social temperament was used only by two groups, which may indicate a lack 
of clarity on what this trait means, why it is important, or how it is differentiated from the concept of social cognition or other traits, and this may point to the need for further instruction concerning this trait. Six groups used both types of causal arrows explicitly in their maps, while the other groups indicated only one type of arrow, however arrows were going in both directions in three maps. In the six causal maps in which the two different types of arrows were marked, we found six conceptually wrong connections (wrong type or wrong direction) among a total of 133 arrows. Furthermore, a number of connections were made that require further elaboration. For example, one student group linked "meat-based diet - selects for - genes involved in the development of this trait". It is unclear which genes for which trait they are considering in this case, and students can be prompted to think about possible mediating phenotypic traits (body, brain, behavior) in this causal chain. Connecting causal maps with student written explanations may help to further elucidate their reasoning.

One of these groups also presented their causal map on the blackboard after group work. Many students contributed to a discussion by pointing out the four arrows in the map that were wrong, and suggesting a number of arrows that could still be added to the causal map. We noted no difficulties in understanding the meaning of the arrows from this classroom discussion.

At the end of the causal mapping and final session, the authors highlighted to students that such causal maps are never quite "complete", that in the causal map on the board, there are still many more arrows we could add, and that biologists use such maps to identify and disentangle the multitude of factors that may play a role in the evolution and development of particular traits of interest, in humans and other organisms.

This exploratory classroom intervention indicates the potential for student understanding of the causal mapping method, including the different nature of the two causal relationships. Future opportunities are to scaffold the introduction of the causal mapping tool on a trait by trait basis throughout a unit on human evolution, to assess individual student explanations and construction of causal maps on several examples of human traits, to have students "translate" narrative accounts of trait evolution into causal maps or vice versa, or to probe for student understanding of the causal roles of each factor using reflection questions highlighted in the previous sections. 
Anecdotally, the teacher spontaneously adopted the causal mapping technique in another one of her 10th grade biology classrooms, apparently leading to productive discussions on the complex nature of relationships during human evolution. This indicates that this teaching tool has the potential to spread in educational settings with rather minimal introduction and teacher training.

\section{Considerations for further research and development}

In this paper, we aimed to draw attention to the educational opportunities provided by an explicit consideration of behavior as a causal factor in the evolution of certain traits. This role of behavioral variation in affecting evolutionary trajectories has been the subject of much discussion throughout the history of evolutionary thought, and has attracted new attention in recent decades. Particularly in the realm of human evolution, many traits of concern are linked to behaviors whose emergence cannot be understood by referring to chance genetic mutations alone, such as upright walking, tool making and many other behavioral and cultural traits. We argued that some concerns for teleological reasoning in student explanations may stem from the lack of opportunity given to students to explicitly link behaviors and other proximate mechanisms to the emergence of traits in populations through natural selection. After all, teleological language seems to stem from our everyday experience - as biological organisms - of needs and behavioral responses to needs. We argued that those behavioral responses to perceived needs, or goal-directed behaviors, are important elements in the causal chain leading to the natural selection of morphological traits or genetic dispositions that favor or enable the adaptive behavioral responses to such needs.

We presented a teaching tool for causal mapping that has the potential to elicit and expand student understanding about the role of behaviors, body and brain features, genes as well as the mechanisms of variation and natural selection in the evolution of traits. Such causal mapping may also provide the opportunity to teach about various concepts in evolutionary biology as well as other topics in the biology curriculum in an integrated fashion, and has the potential to cultivate a more decentralized mindset about the emergence of phenotypes and adaptations in development and evolution. 
Our preliminary classroom case studies indicate that the use of this teaching tool, in combination with other tools that cultivate population thinking, can yield productive classroom discussions and allows assessment of student understanding in various ways. Furthermore, students were able to understand and apply the causal mapping technique, including the meaning of the different causal relationships, after minimal instruction and minimal previous exposure to concepts in evolutionary biology and anthropology.

We aim to expand the insights gained in the exploratory case study that we reported in this article. Specifically, we have continued to produce causal map "vignettes" for a range of traits and themes in human evolution, which can help to scaffold and transfer the causal mapping method throughout a unit on human evolution, from upright walking to more complex themes like adaptations to group life, to the complex causal relationships that continue to shape the cultural evolution of our species in the present and future (see supplemental materials, file 6 , additional material 7). Future research may use the causal mapping technique as an assessment tool to assess the variation in individual student understanding, identify prevailing misconceptions including teleological reasoning and other common misconceptions in evolution education, and to develop further instructional techniques to help overcome them. Within our DBIR project we will continue to develop and evaluate teacher training and instructional guidance to enable teachers to flexibly use and adapt the causal mapping method in their evolution classrooms.

\section{List of abbreviations}

DBIR - Design-based Implementation Research

PCK - Pedagogical Content Knowledge

\section{Declarations}

\section{Supplementary materials}

Supplementary materials for this preprint are available on Edarxiv.

\section{Competing interests}

The authors declare that they have no competing interests with respect to the conclusions in this manuscript. 


\section{Funding}

The authors received no funding for the classroom interventions reported in this manuscript nor for the preparation of the manuscript.

\section{Authors' contributions}

Both authors were equally involved in the conceptualization of the teaching tools, preparation and observation of classroom interventions. The first author took the lead in the development of the manuscript and analysis of classroom observations.

\section{Acknowledgements}

We thank Silke Duden for giving us the opportunity to collaborate with her and develop and test interventions with her classrooms, and Sebastian Tempelmann for helpful comments on an earlier version of the manuscript.

\section{References}

Andrews, T. M., Kalinowski, S. T., \& Leonard, M. J. (2011). "Are Humans Evolving?" A Classroom Discussion to Change Student Misconceptions Regarding Natural Selection. Evolution: Education and Outreach, 4(3), 456-466. https://doi.org/10.1007/s12052-011-0343-4

Antón, S. C., \& Josh Snodgrass, J. (2012). Origins and Evolution of Genus Homo. New perspectives. Current Anthropology, 53(S6), S479-S496. https://doi.org/10.1086/667692

Aunger, R. V., \& Curtis, V. (2008). Kinds of behaviour. Biology and Philosophy, 23(3), 317-345. https://doi.org/10.1007/s10539-007-9108-4

Baack, K., Becker, A., Eckebrecht, D., Keßling, J., Koch, M., Maier, A., \& Roßnagel, G. (2016). Natura Oberstufe. Biologie für Gymnasium. Stuttgart, Germany: Ernst Klett Verlag.

Badyaev, A. V. (2009). Evolutionary significance of phenotypic accommodation in novel environments: An empirical test of the Baldwin effect. Philosophical Transactions of the Royal Society B: Biological Sciences, 364(1520), 1125-1141. https://doi.org/10.1098/rstb.2008.0285

Barnes, M. E., Evans, E. M., Hazel, A., Brownell, S. E., \& Nesse, R. M. (2017). Teleological reasoning, not acceptance of evolution, impacts students' ability to learn natural selection. Evolution: Education and Outreach, 10(1), 7. https://doi.org/10.1186/s12052-017-0070-6

Bayer, C. N., \& Luberda, M. (2016). Measure, then show: Grasping human evolution through an inquiry-based, data-driven hominin skulls lab. PLoS ONE, 11(8), 1-25.

https://doi.org/10.1371/journal.pone.0160054

Besterman, H., \& Baggot la Velle, L. (2007). Using human evolution to teach evolutionary theory. Journal of Biological Education, 41(2), 76-81. https://doi.org/10.1080/00219266.2007.9656066

Cañas, A. J., Novak, J. D., \& González, F. M. (2004), Concept Maps: Theory, Methodology, Technology. Proc. of the First Int. Conference on Concept Mapping. Pamplona, Spain. 
Carvalho, S., Biro, D., Cunha, E., Hockings, K., McGrew, W. C., Richmond, B. G., \& Matsuzawa, T. (2012). Chimpanzee carrying behaviour and the origins of human bipedality. Current Biology, 22(6), R180-R181. https://doi.org/10.1016/j.cub.2012.01.052

Chudek, M., \& Henrich, J. (2011). Culture-gene coevolution, norm-psychology and the emergence of human prosociality. Trends in Cognitive Sciences, 15(5), 218-226.

https://doi.org/10.1016/j.tics.2011.03.003

Coley, J. D., \& Tanner, K. (2015). Relations between intuitive biological thinking and biological misconceptions in biology majors and nonmajors. CBE Life Sciences Education, 14(1), 1-19. https://doi.org/10.1187/cbe.14-06-0094

Cooper, R. A. (2017). Natural selection as an emergent process: instructional implications. Journal of Biological Education, 51(3), 247-260. https://doi.org/10.1080/00219266.2016.1217905

Corning, P. A. (2014). Evolution "on purpose": How behaviour has shaped the evolutionary process. Biological Journal of the Linnean Society, 112(2), 242-260. https://doi.org/10.1111/bij.12061

Coward, F., \& Grove, M. (2011). Beyond the tools: Social innovation and hominin evolution. PaleoAnthropology, 111-129. https://doi.org/10.4207/PA.2011.ART46

Dewsbury, D. A. (1992). Essay on Contemporary Issues in Ethology: On the Problems Studied in Ethology, Comparative Psychology, and Animal Behavior. Ethology, 92(2), 89-107. https://doi.org/10.1111/j.1439-0310.1992.tb00951.x

Dobzhansky, T. 1955. Evolution, genetics and man. New York, NY, USA: Wiley.

Dukas, R. (2013). Effects of learning on evolution: Robustness, innovation and speciation. Animal Behaviour, 85(5), 1023-1030. https://doi.org/10.1016/j.anbehav.2012.12.030

Eirdosh, D., \& Hanisch, S. (2019). Global ESD. http://www.globalesd.org

Evans, E. M., \& Rosengren, K. (2018). Cognitive Biases or Cognitive Bridges? Intuitive Reasoning in Biology. In K. Kampourakis \& M. J. Reiss (Eds.), Teaching Biology in Schools. Global Research, Issues, and Trends. New York, NY, USA: Routledge. https://doi.org/10.4324/9781315110158

Fishman, B. J., Penuel, W. R., Allen, A., \& Sabelli, N. (2013). Design-Based Implementation Research: An Emerging Model for Transforming the Relationship of Research and Practice. National Society for the Study of Education, 112(2), 136-156.

Fuentes, A. (2019=.Gouvea, J. S., \& Simon, M. R. (2018). Challenging Cognitive Construals: A Dynamic Alternative to Stable Misconceptions. CBE-Life Sciences Education, 17(2), ar34. https://doi.org/10.1187/cbe.17-10-0214

Griffiths, P. E., \& Gray, R. D. (1994). Developmental Systems and Evolutionary Explanation. The Journal Of Philosophy, 91(6), 277-304.

Hasson, O. (2000). Knowledge, information, biases and signal assemblages. In Y. Espmark, T. Amundsen, \& G. Rosenqvist (Eds.), Animal signals: Signalling and signal design in animal communication (pp. 445-463). Trondheim, Norway: Tapir Academic Press. 
Hladký, V., \& Havlíček, J. (2013). Was Tinbergen an Aristotelian? Comparison of Tinbergen's Four Whys and Aristotle's Four Causes. Human Ethology Bulletin, 28(4), 3-11.

Humphrey, N., Skoyles, J. R., \& Keynes, R. (2005). Human Hand-Walkers: Five Siblings Who Never Stood Up. CPNSS Discussion Paper. https://doi.org/10.1111/j.0006-341X.2005.171_1.X

Jablonka, E., \& Lamb, M. J. (2005). Evolution in Four Dimensions. Genetic, Epigenetic, Behavioral, and Symbolic Variation in the History of Life. Cambridge, MA, USA: MIT Press.

Jamieson, A., \& Radick, G. (2017). Genetic Determinism in the Genetics Curriculum: An Exploratory Study of the Effects of Mendelian and Weldonian Emphases. Science and Education, 26(10), 1261-1290. https://doi.org/10.1007/s11191-017-9900-8

Kampourakis, K., \& Nehm, R. H. (2014). History and philosophy of science and the teaching of evolution: Students' conceptions and explanations. In: Matthews, M.R. (ed.) International handbook of research in history, philosophy and science teaching (pp. 377-399). Springer, Dordrecht.

Karasik, L. B., Adolph, K. E., Tamis-Lemonda, C. S., \& Bornstein, M. H. (2010). WEIRD walking: Cross-cultural research on motor development. Behavioral and Brain Sciences, 33(2-3), 95-96. https://doi.org/10.1017/S0140525X10000117

Kelemen, D. (2012). Teleological Minds: How Natural Intuitions about Agency and Purpose Influence Learning about Evolution. In: K. S. Rosengren, S. K. Brem, E. M. Evans, \& G. M. Sinatra (Eds.), Evolution Challenges: Integrating Research and Practice in Teaching and Learning about Evolution. Oxford University Press. https://doi.org/10.1093/acprof:oso/9780199730421.003.0004

Kendal, J. R., Tehrani, J. J., \& Odling-Smee, J. (2011). Human niche construction. Papers of a Theme issue. Phil. Trans. R. Soc. B, 366(1566), 783-934. Retrieved from https://royalsocietypublishing.org/toc/rstb/2011/366/1566

Kingdon, J. (2003). Lowly Origin: Where, When, and Why Our Ancestors First Stood Up. Princeton University Press.

Koops, K., Visalberghi, E., \& Van Schaik, C. P. (2014). The ecology of primate material culture. Biology Letters, 10(11), 3-6. https://doi.org/10.1098/rsbl.2014.0508

LAFFTRIP Videos (2016). Monkey with a dozen oranges.

https://www.youtube.com/watch?v=gDHfU6wPNXk. Accessed 08 September 2019.

Laland, K. N., \& Sterelny, K. (2006). Perspective: Seven Reasons (Not) To Neglect Niche Construction. Evolution, 60(9), 1751-1762. https://doi.org/10.1111/j.0014-3820.2006.tb00520.x

Laland, K. N., Odling-Smee, J., \& Myles, S. (2010). How culture shaped the human genome: Bringing genetics and the human sciences together. Nature Reviews Genetics, 11(2), 137-148. https://doi.org/10.1038/nrg2734

Laland, K. N., Sterelny, K., Odling-Smee, J., Hoppitt, W. J. E., \& Uller, T. (2011). Cause and Effect in Biology Revisited: Is Mayr's Proximate-Ultimate Dichotomy Still Useful? Science, 334(6062), 1512-1516. https://doi.org/10.1126/science.1210879 
Laland, K. N., Odling-Smee, J., Hoppitt, W. J. E., \& Uller, T. (2012). More on how and why: Cause and effect in biology revisited. Biology and Philosophy, 28(5), 719-745.

https://doi.org/10.1007/s10539-012-9335-1

Laland, K. N., Uller, T., Feldman, M. W., Sterelny, K., Müller, G. B., Moczek, A. P., ... Odling-Smee, J. (2015). The extended evolutionary synthesis: its structure, assumptions and predictions. Proc. R. Soc. B, 282(1813), 20151019. https://doi.org/10.1098/rspb.2015.1019

Legare, C. H., Lane, J. D., \& Evans, E. M. (2013). Anthropomorphizing Science: How Does It Affect the Development of Evolutionary Concepts? Merrill-Palmer Quarterly, 59(2), 168-197.

https://doi.org/10.1353/mpq.2013.0009

Legare, C. H., Opfer, J. E., Busch, J. T. A., \& Shtulman, A. (2018). A Field Guide for Teaching Evolution in the Social Sciences. Evolution and Human Behavior, 39(3), 257-268.

https://doi.org/10.1016/i.evolhumbehav.2018.01.002

Liu, S.-H., \& Lee, G.-G. (2013). Using a concept map knowledge management system to enhance the learning of biology. Computers \& Education, 68, 105-116.

http://doi.org/10.1016/j.compedu.2013.05.007

Lombrozo, T. (2009). Explanation and categorization: How "why?" informs "what?" Cognition, 110(2), 248-253. https://doi.org/10.1016/j.cognition.2008.10.007

Lombrozo, T., \& Gwynne, N. Z. (2014). Explanation and inference: mechanistic and functional explanations guide property generalization. Frontiers in Human Neuroscience, 8(September), 1-12. https://doi.org/10.3389/fnhum.2014.00700

Lombrozo, T. \& Vasilyeva, N. (2017). Causal Explanation. In: Waldmann, M. (ed.) The Oxford Handbook of Causal Reasoning. Oxford, UK: Oxford University Press.

https://doi.org/10.1093/oxfordhb/9780199399550.013.22

Louca, L., Elby, A., Hammer, D., \& Kagey, T. (2004). Epistemological Resources: Applying a New Epistemological Framework to Science Instruction. Educational Psychologist, 39(1), 57-68. https://doi.org/10.1207/s15326985ep3901_6

Maynard Smith, J., \& Harper, D. (2003). Animal Signals. Oxford Series in Ecology and Evolution. Oxford, UK: Oxford University Press.

Mayr, E. (1961). Cause and Effect in Biology. Science, 134(3489), 1501-1506.

https://doi.org/10.1126/science.134.3489.1501

Mayr, E. 1970. Populations, Species, and Evolution. An Abridgment of Animal Species and Evolution. Cambridge, MA: Harvard University Press.

Mayr, E. (1974). Teleological and teleonomic: a new analysis. In C. RS \& W. MW (Eds.), A Portrait of Twenty-five Years. Boston studies in the philosophy of science, Vol. 14. (Vol. 14, pp. 91-117). Boston, MA, USA: Reidel.

Mesoudi, A. (2011). Cultural Evolution: How Darwinian Theory Can Explain Human Culture and Synthesize the Social Sciences. Chicago, USA: University of Chicago Press. 
Moczek, A. P., Sultan, S., Foster, S., Ledón-Rettig, C., Dworkin, I., Nijhout, H. F., ... Pfennig, D. W. (2011). The role of developmental plasticity in evolutionary innovation. Proceedings of the Royal Society B: Biological Sciences, 278(1719), 2705-2713. https://doi.org/10.1098/rspb.2011.0971

Nehm, R. H., Ha, M., Rector, M., Opfer, J., Perrin, L., Ridgway, J., \& Mollohan, K. (2010). Scoring Guide for the Open Response Instrument (ORI) and Evolutionary Gain and Loss Test (EGALT).

Nehm, R. H., Beggrow, E. P., Opfer, J. E., \& Ha, M. (2012). Reasoning About Natural Selection: Diagnosing Contextual Competency Using the ACORNS Instrument. The American Biology Teacher, 74(2), 92-98. https://doi.org/10.1525/abt.2012.74.2.6

Nettle, D. (2010). Understanding of evolution may be improved by thinking about people. Evolutionary Psychology, 8(2), 205-228. https://doi.org/10.1177\%2F147470491000800206

O'Brien, M. J., \& Laland, K. N. (2012). Genes, Culture, and Agriculture. An Example of Human Niche Construction. Current Anthropology, 53(4), 434-470. https://doi.org/10.1086/666585

Odling-Smee, J., Laland, K. N., \& Feldman, M. W. (2003). Niche construction. The neglected Process in Evolution. Princeton, New Jersey, USA: Princeton University Press.

Odling-Smee, J., \& Laland, K. N. (2011). Ecological Inheritance and Cultural Inheritance: What Are They and How Do They Differ? Biological Theory, 6(3), 220-230.

https://doi.org/10.1007/s13752-012-0030-x

Ojalehto, b., Waxman, S. R., \& Medin, D. L. (2013). Teleological reasoning about nature: Intentional design or relational perspectives? Trends in Cognitive Sciences, 17(4), 166-171.

https://doi.org/10.1016/j.tics.2013.02.006

Oyama, S., Griffiths, P. E., \& Gray, R. D. (2001). Cycles of contingency. Developmental Systems and Evolution. Cambridge, MA: MIT Press.

Pearl, J., \& Mackenzie, D. (2018). The book of why: the new science of cause and effect. New York, NY, USA: Basic Books.

Penuel, W. R., \& Gallagher, D. J. (2017). Creating Research Practice Partnerships in Education. Cambridge, MA: Harvard Education Press.

Petrosino, A. J., Lucero, M. M., \& Mann, M. J. (2015). Decentralized thinking and understanding of evolution in K-12 evolution education. Evolution: Education and Outreach, 8(1), 2.

https://doi.org/10.1186/s12052-014-0028-x

Pfennig, D. W., Wund, M. A., Snell-Rood, E. C., Cruickshank, T., Schlichting, C. D., \& Moczek, A. P. (2010). Phenotypic plasticity's impacts on diversification and speciation. Trends in Ecology and Evolution, 25(8), 459-467. https://doi.org/10.1016/j.tree.2010.05.006

Pigliucci, M. (2009). An extended synthesis for evolutionary biology. Annals of the New York Academy of Sciences, 1168, 218-228. https://doi.org/10.1111/j.1749-6632.2009.04578.x

Pittendrigh, C.S. (1958). Adaptation, natural selection and behavior. In: Roe, A., Simpson, G.G., eds. Behavior and evolution. New Haven, CT: Yale University Press, 390-416. 
Pobiner, B., Beardsley, P. M., Bertka, C. M., \& Watson, W. A. (2018). Using human case studies to teach evolution in high school A. P. biology classrooms. Evolution: Education and Outreach, 11(3). https://doi.org/10.1186/s12052-018-0077-7

Pobiner, B. (2016). Accepting, understanding, teaching, and learning (human) evolution: Obstacles and opportunities. American Journal of Physical Anthropology, 159, S232-S274.

https://doi.org/10.1002/ajpa.22910

Rachwani, J., Hoch, J. E., \& Adolph, K. E. (in press). Action in development: Variability, flexibility, and plasticity. In Tamis-LeMonda, C. S., \& Lockman, J. J. (Eds.). Handbook of infant development. Cambridge University Press.

rbtha (2012). Stages of learning to walk. https://www.youtube.com/watch?v=jlzuy9fcf1k\&t=. Accessed 08 September 2019.

Roe, A., Simpson, G.G. (1958). Behavior and evolution. New Haven, CT: Yale University Press.

Scoville, A. G., \& Pfrender, M. E. (2010). Phenotypic plasticity facilitates recurrent rapid adaptation to introduced predators. Proceedings of the National Academy of Sciences, 107(9), 4260-4263. https://doi.org/10.1073/pnas.0912748107

Shapiro, L. J., Cole, W. G., Young, J. W., Raichlen, D. A., Robinson, S. R., \& Adolph, K. E. (2014). Human quadrupeds, primate quadrupedalism, and Uner Tan Syndrome. PLoS ONE, 9(7), 17-20. https://doi.org/10.1371/journal.pone.0101758

Smithsonian Institution (2019). What does it mean to be human? Walking Upright. http://humanorigins.si.edu/human-characteristics/walking-upright. Accessed 22 October 2019.

Snell-Rood, E. C. (2013). An overview of the evolutionary causes and consequences of behavioural plasticity. Animal Behaviour, 85(5), 1004-1011. https://doi.org/10.1016/j.anbehav.2012.12.031

Sockol, M. D., Raichlen, D. A., \& Pontzer, H. (2007). Chimpanzee locomotor energetics and the origin of human bipedalism. PNAS - Proceedings of the National Academy of Sciences, 104(30), 12265-12269. https://doi.org/10.1073/pnas.0703267104

Tan, U. (2010). Uner Tan Syndrome: History, Clinical Evaluations, Genetics, and the Dynamics of Human Quadrupedalism. The Open Neurology Journal, 4(1), 78-89.

https://doi.org/10.2174/1874205x01004010078

Tkgd2007 (2008). Human evolution. Creative Commons Attribution-Share Alike 3.0 Unported license, https://creativecommons.org/licenses/by-sa/3.0/deed.en.

https://commons.wikimedia.org/wiki/File:Human_evolution.svg. Accessed 08 September 2019.

Thompson, J. N. (2010). Four Central Points About Coevolution. Evolution: Education and Outreach, 3(1), 7-13. https://doi.org/10.1007/s12052-009-0200-x

Tinbergen, N. (1963). On aims and methods of Ethology. Zeitschrift Für Tierpsychologie, 20(4), 410-433. https://doi.org/10.1111/j.1439-0310.1963.tb01161.x 
Tombre, .I M., Oudman, T., Shimmings, P., Griffin, L., \& Prop, J. (2019). Northward range expansion in spring-staging barnacle geese is a response to climate change and population growth, mediated by individual experience. Global Change Biology, 00, 1- 14. https://doi.org/10.1111/gcb.14793

Van Zele, E., Lenaerts, J., \& Wieme, W. (2004). Improving the usefulness of concept maps as a research tool for science education. International Journal of Science Education, 26(9), 1043-1064. https://doi.org/10.1080/1468181032000158336

Varella, M. A. C. (2018). The biology and evolution of the three psychological tendencies to anthropomorphize biology and evolution. Frontiers in Psychology, 9(OCT), 1-21.

https://doi.org/10.3389/fpsyg.2018.01839

Werth, A. (2009). Clearing the highest hurdle: Human-based case studies broaden students' knowledge of core evolutionary concepts. The Journal of Effective Teaching, 9(2), 38-53.

Werth, A. (2012). Avoiding the pitfall of progress and associated perils of evolutionary education. Evolution: Education and Outreach, 5(2), 249-265. https://doi.org/10.1007/s12052-012-0417-y

West-Eberhard, M. J. (1998). Evolution in the light of developmental and cell biology, and vice versa. Proceedings of the National Academy of Sciences of the United States of America, 95(15), 8417-8419. https://doi.org/10.1073/pnas.95.15.8417

Whiten, A., \& Erdal, D. (2012). The human socio-cognitive niche and its evolutionary origins. Philosophical Transactions of the Royal Society B: Biological Sciences, 367(1599), 2119-2129. https://doi.org/10.1098/rstb.2012.0114

Wright, L. (1976). Teleological Explanations: An Etiological Analysis of Goals and Functions. University of California Press.

Xu, D., \& Chi, M. T. H. (2016). Bridging Emergent Attributes and Darwinian Principles in Teaching Natural Selection. Universal Journal of Educational Research, 4(5), 1117-1121.

https://doi.org/10.13189/ujer.2016.040522

Zeder, M. A. (2016). Domestication as a model system for niche construction theory. Evolutionary Ecology, 30(2), 325-348. https://doi.org/10.1007/s10682-015-9801-8

Ziadie, M. A., \& Andrews, T. C. (2018). Moving evolution education forward: A systematic analysis of literature to identify gaps in collective knowledge for teaching. CBE Life Sciences Education, 17(1). https://doi.org/10.1187/cbe.17-08-0190

Zohar, A., \& Ginossar, S. (1998). Lifting the Taboo Regarding Teleology and Anthropomorphism in Biology Education - Heretical Suggestions. Science Education, 82, 679-697.

https://doi.org/10.1002/(SICI)1098-237X(199811)82:6\%3C679::AID-SCE3\%3E3.0.CO;2-E 